\title{
Miscelánea
}

\section{Las Nuevas “caras” (mianzi, 面子) en los chinos de España: reciprocidad y mercado}

\section{The New "Faces" (Mianzi, 面子) of Chinese people in Spain: Reciprocity and Market}

\author{
Jorge MORAGA REYES \\ Universidad Complutense de Madrid \\ simpulum@yahoo.com
}

Recibido: 15 de enero de 2011

Aceptado: 10 de noviembre 2011

\section{Resumen}

A partir de una distinción identitaria entre los inmigrantes chinos, según sea su origen el puerto de Wenzhou o las cordilleras de Qingtian — vecinas ambas en la provincia de Zhejiang y principales núcleos emigratorios hacia España-, analizo la presencia de estructuras "étnicas" de reciprocidad que en el contexto de la migración transnacional han comenzado a estimular el ingreso en los patrones de la racionalidad instrumental y el consumo. En este artículo me centraré en una de ellas: mianzi (面子) o cara, principal fuente de capital simbólico y soporte de la posición de prestigio entre los chinos. Intentaré dar cuenta de algunas de sus instituciones configuradoras y de las legitimidades que construyen su valor. En la amplitud de sentidos y prácticas que comprende, mianzi se esboza como una estructura que lejos de vivir un debilitamiento por su ingreso en la modernidad occidental, muestra plena vigencia adaptándose a nuevos espacios sociales ${ }^{1}$.

Palabras clave: migración china, cara (mianzi, 面子), reciprocidad, mercado, capital simbólico, modernización occidental.

\begin{abstract}
The place of origin - Wenzhou port or Qingtian mountain range, both located in the province of Zhejiang - is a mark of identity among the Chinese immigrants in Spain. In this transnational immigration context, I analyze the way the presence of "ethnic" structures of reciprocity has started to stimulate migrants to merge with instrumental and consumption rationality patterns. As one of those patterns, Mianzi (面子) or face is the main source of symbolic capital and the base for the high prestige among Chinese people. In this article, I discuss some of the institutions and legitimacies that constitute the values of mianzi. Along with a wide range of meanings and practices, mianzi becomes a structure that far from experiencing a weakness because its entrance in Western modern age, adjusts to new social spaces and accounts for its relevance.
\end{abstract}

${ }^{1}$ El trabajo de campo ha sido realizado en Asturias y Madrid durante los últimos dos años. 
Keywords: chinese migration, face (mianzi, 面子), reciprocity, market, symbolic capital, western modernity.

Referencia normalizada: Moraga Reyes, J. (2012). “Las Nuevas “caras” (mianzi, 面子) en los chinos de España: reciprocidad y mercado". Revista de Antropología Social, 21: 217-250.

SUMARIO: 1. ¿Qué es eso llamado cara? 2. Mianzi v/s. Liăn. 3. El empresario-ru. 4. A modo de conclusión. 5. Referencias bibliográficas.

\section{1. ¿Qué es eso llamado cara?}

Si otros conceptos característicos de los estudios chinos, como guānxi (relaciones, 关系) o jiā (familia, 家) han provocado múltiples desvaríos y barrancos confusionales, no se puede decir menos de mianzi (面子), generalmente traducido como cara. Pese a que no existen estudios históricos específicos, ni se conoce en detalle la variación de su sentido a través de los siglos, es innegable su profundidad temporal y su peso en la cultura.

La reflexividad sobre el término, obviamente, es una inquietud bastante más reciente, en gran parte motivada por el contacto con Occidente. Entre los fundadores de tal "crítica" destaca el propio Lu Xun, padre de la literatura china moderna y principal abanderado del movimiento cultural del 4 de mayo de $1919^{2}$, quien no dudó en consagrar una obra íntegra — 说面子, On Face en su traducción inglesaal análisis o más bien a las incertidumbres en torno a una noción digna de la etnometodología: “¿Pero qué es esta cosa llamada cara? —advertía_, está muy bien si no te detienes a pensar, pero mientras más lo piensas más crece la confusión" (Lu Xun, 1934: 129) $)^{3}$.

En esa misma trinchera obstinada en destacar su irreductibilidad cultural, tampoco se quedó atrás Lin Yü-Tang, escritor y gran difusor de la cultura china en Europa y Estados Unidos. Con orgullosa humildad, en My Country and My People aseguraba que es "imposible definir cara". Apelando a su carácter "abstracto e intangible", se refería a ella como "el más delicado estándar de comportamiento por el cual es regulada la interrelación social china" (Lin 1935: 200-202) ${ }^{4}$.

Pese a tan etérea y mentada esencia, su contemporánea Hu Hsien-Chin la acotó por fin a una forma de construcción del valor social, a la representación del prestigio, a las posiciones de cada sujeto en una estructura de relaciones basada en expectativas definidas con respecto a un otro. No se trataría entonces de un fundamento inmodificable sino de una estructura variable según el momento histórico y el grupo del que se trate. Analizando a los chinos migrantes en la Norteamérica de los años

${ }^{2}$ Nunca está de más apuntar que Lu Xun es originario justamente de Zhejiang. Nació en Shaoxing, en 1881, en una familia de letrados reducida a la pobreza.

3 "But what is this thing called face?, it is very well if you don't stop to think, but the more you think the more confused you grow".

4 "Here we arrive at the most curious point of Chinese social psychology. Abstract and intangible, it is yet the most delicate standard by which Chinese social intercourse is regulated". 
40 del siglo pasado, Hu constató, por ejemplo, que para evaluar la conducta correcta y la posición de alguien apelaban a dos significantes, a dos diferentes criterios de valor: liăn (脸) y mianzi (面子).

La distinción se constata hasta hoy en los chinos actuales y a partir de ella es posible sostener que: "(mien-tzu $)^{5}$ se refiere a la clase de prestigio que es enfatizada en este país [Estados Unidos]: una reputación alcanzada a través de los logros de una vida por medio del éxito y la ostentación". Liăn ${ }^{6}$, por su parte, "representa la confianza de la sociedad en la integridad del carácter moral de ego, cuya pérdida hace imposible para él funcionar adecuadamente con la comunidad. Lien es a la vez una sanción social que hace cumplir patrones morales y una sanción internalizada" (Hu, 1944: 45). Es necesario explicitar que ambos conceptos están indisolublemente vinculados, retroalimentándose, por lo cual en algunos contextos se utilizan indistintamente.

Pero el halo particularista ha traspasado casi toda la producción crítica que envuelve cara. Entre otros, un clásico es el estudio de Ho David Yau-fai, que destaca la radical otredad del concepto alejándolo de otros similares utilizados por la sociología occidental, como "autoridad" y "status". Para Ho la "autoridad" y el "status" siempre responderían a un "control legítimo", "institucionalizado" y "unidireccional". En cambio cara respondería a un poder basado en la persona y por esa razón sería "invariablemente recíproco". Es decir, aunque su poder derive de una relación de autoridad institucionalmente "legítima", a menudo sus obligaciones se extienden más allá del rol asignado formalmente por ella. Entonces, el valor de cara en China tendría una marcada orientación a la reciprocidad de las relaciones, a la dependencia mutua y la búsqueda de protección (Ho, 1976: 874 y 883; Ho, 1974: 240-251).

Sin negar la pertinencia de Ho al describirla en un marco de relaciones propio de la lógica del don (Mauss, 2008), es cuestionable que subraye ese hecho como una especie de fractura fundamental entre oriente y occidente, apelando muchas veces sin decirlo a otra disyunción tan dudosamente absoluta, esta vez entre tradición y modernidad.

Recordemos que Mauss introduce el "primitivo" tema de la constitución del lazo social a partir de las obligaciones de dar-recibir-y-devolver un don. Al analizar la circularidad de las relaciones así fundadas en sociedades "arcaicas", postula que este principio detonaría a su vez dos movimientos: uno de cercanía en el reparto solidario, y otro de distancia social, de lejanía, al generar una deuda en quien recibe, poniendo jerárquicamente al que dona en una posición de superioridad, inaugurando una relación agonística (Mauss, 2008: 148).

Se tiende entonces a pensar que la estructura de mianzi, en tanto enlaza actores y los predispone a operar según principios de reciprocidad, se establecería y mostraría su eficacia solo en un contexto ajeno al proceso de la modernización occidental. Sus misteriosos y arcaicos mecanismos, al ser leídos como una verdadera opacidad en

${ }^{5} \mathrm{Hu}$ emplea el sistema de transcripción Wade-Giles. En este trabajo, el pinyin. Mien-tzu = mianzi $=$ 面子. Para escribir los nombres de los autores chinos respetaré la norma de las ediciones originales.

${ }^{6}$ Lien $=$ liăn $=$ 脸. 
un contexto modernizante, debieran por lo tanto tender a disolverse en la medida que ingresan en los nuevos parámetros. Eso es justamente lo que pretendo confrontar - y si es posible, disentir-, pues la lógica del don presente en mianzi permea y se instala por diferentes vías en la sociedad moderna, y también a la inversa, la racionalidad "contable" infiltra los espacios del don. Dicho de otra manera, el intercambio mercantil y el contrato, por una parte, y lo no-contractual ni "negociable", la reciprocidad, por otra, parecen ensamblar como dos bases necesarias (Mauss 2008: 160; Godelier 1996: 53, 107) que sostienen la vida social del mundo chino en España ${ }^{7}$.

Esta tarea sin duda ofrece complicaciones que no verán aquí su fin, pero ejemplifica el hilo de tensión que pretendo seguir: ¿Cómo opera el irónicamente llamado espíritu del don, una estructura de relaciones recíprocas en general y el don agonístico en particular en los chinos inmigrantes en una sociedad moderna?

Si ese es el objetivo, más allá de la obstinación por definir cara y sus particularismos - lo que en muchas ocasiones solo ha empantanado su estudio-, parece más cuerdo ponerla en juego como capital simbólico, dando cuenta de los discursos y prácticas que se legitiman y se explican por su capacidad operatoria, al ser reconocida por ciertos actores como un valor (Bourdieu, 1997: 173). Trataré de esbozar entonces algunos elementos que podrían iluminar las condiciones de producción de esas disposiciones, cómo se ha podido producir la "creencia" en tal valor, qué labores socializadoras, qué instituciones y qué acciones han sido necesarias para que emerjan unos agentes dotados de esquemas de percepción y de valoración que les permitirán reconocer y actuar según sus leyes, las de mianzi, en la intensa pugna por el control, la hegemonía y la posición social que se vive en este grupo inmigrante ${ }^{8}$.

\section{Mianzi v/s Liăn}

Nadie cuestiona que junto a las estructuras de guānxi (关系) ${ }^{9}$, con sus reglas de conformación y sostenimiento, el hecho de tener o no tener cara, el aumentarla o perderla es la principal fuente de diferenciación interna en el mundo chino (Goffman, 1955; Hwang, 1987; Yan, 1996; Earley, 1997; Guthrie, 1998; Hutchins et al., 2002; Beltrán, 1996 y 2003; Hammond y Glend, 2004; Millington, 2006; Hsu, 2007). Sin embargo, el concepto cara se torna conflictivo al intentar definir sus límites y contenidos, y más aún, los posibles núcleos de valor que guían las acciones necesarias para construirla. Como podría esperarse, en tanto se trata nada menos que de investir la representación del prestigio y la posición social, la propia palabra

${ }^{7}$ Mauss va más lejos, pues cree haber demostrado no solo que la moral y la economía del don funcionan aún en la actualidad de "manera constante y, por así decirlo, subyacente", sino también haber encontrado en las obligaciones del don las "rocas humanas" sobre las cuales son construidas las sociedades (Mauss, 2008: 148).

${ }^{8}$ Una muestra de ello es la profunda fragmentación y lucha interna que caracteriza sus movimientos asociativos (Nieto, 2007).

${ }^{9}$ Guānxi: relaciones. Se refiere a la obligación social de construir una red personal de relaciones, inserta en un sistema de reciprocidades y de la cual también dependerá la cara individual. Un análisis de los mecanismos de guānxi, al menos entre los chinos de Asturias, lo he realizado en: Moraga, 2010. 
que lo designa es un objeto en pugna. Si bien cara es mencionada por todos como la máxima expresión del valor social, su contenido no suele responder a una unidad. Más bien al contrario, emergen los problemas propios de un concepto occidental que no existe en chino, a partir del cual es necesario rastrear sus fisuras y versiones, según sea el dispositivo de producción discursiva al que apela cada hablante.

La primera gran divergencia se refiere al peso que se le atribuye a la distinción entre liăn y mianzi. Como mencionaba, el primero remite a los aspectos de valores, al cumplimiento de las pautas éticas esperadas por un colectivo, a la construcción de una cara "honesta y decente" (Hu, 1944: 62). El segundo se refiere al prestigio, al estatus, al reconocimiento social de la posición de alguien. Ambas requieren la internalización de normas sociales que muchas veces se superponen o están en interrelación. Ambas además se basan en la percepción de la lectura que un Otro -intra y extraétnico - hace de cada cual. Resulta evidente que el peso relativo de cada eje, de liăn o mianzi, y a la vez la conformación de las jerarquías dentro de cada uno de ellos será objeto de disputa entre los chinos inmigrantes.

¿Pero en qué campos discursivos operan estas distinciones sobre los valores del prestigio? ¿Qué se debe hacer en cada uno de ellos para tenerlo y ser reconocido? Las respuestas, o más bien las tendencias de respuestas dependerán del segmento en el que se ponga la mirada y en la valoración que se haga respecto al rol que juegan las concepciones de reciprocidad a las que se apele. Veamos:

Alrededor del 80 por ciento de los chinos en España provienen de la provincia de Zhejiang y han llegado en los últimos 10 años. Me centraré entonces en sus autodefiniciones y oposiciones con otros compatriotas. En Zhejiang existen dos grandes núcleos emigratorios, ambos a lo largo del Río Ou: bajando desde su curso noroeste, en primer lugar el cantón de Qingtian, en la prefectura de Lishui ${ }^{10}$, un conjunto de aldeas rurales y pequeños pueblos ubicados en una zona montañosa, relativamente aislada del resto de China. "Cásate con un qingtianés y comerás patatas toda la vida", dice un refrán aludiendo al humilde pasado de la zona ${ }^{11}$. Y en segundo lugar, al llegar a la desembocadura del río, el puerto de Wenzhou, capital de la municipalidad del mismo nombre, con más de 7 millones de habitantes —un millón y medio en su área metropolitana-, núcleo de un fuerte proceso de modernización: es una zona industrial, comercial y próspera, receptora a su vez de migración interna, especialmente de Qingtian, a partir de la década del 70 del siglo pasado.

Los de Qingtian exhiben la mayoría absoluta en España y participan de una tupida red de relaciones internas muchas veces desconocidas por el resto de sus compatriotas. Conforman una compleja élite con fuertes vínculos empresariales transnacionales. Los de Wenzhou constituyen la principal minoría. Son los vecinos

${ }^{10}$ En la división administrativa de la RPC, Qingtian es un Xian, lo que equivaldría a un cantón o condado. Lishui es uno de los once Shi (ciudades-prefecturas) que componen a su vez la provincia o Sheng de Zhejiang.

${ }^{11}$ Se trata de un dicho popular en China, en referencia a que el dinero no alcanza "ni para comprar arroz". 
ricos de los qingtianeses. Por lo general representan al empresario exitoso y dan vuelo al imaginario del nuevo rico ${ }^{12}$.

Actualmente en Qingtian, y en menor grado en Wenzhou, se vive una suerte de fiebre por la construcción del mito de una identidad migrante que atravesaría históricamente la zona. Funcionarios y élites intelectuales en China y representantes de organizaciones en España se muestran altamente interesados en el rescate folclorista de las tradiciones y en el reforzamiento político de las identidades locales. En todos los casos, el relato de esta "tradición" coincide en un punto: el emigrante sería el sujeto social propio de la zona. Pese a los esfuerzos, históricamente se constata un auge emigratorio internacional más bien tardío, claramente notorio a partir del siglo XX y con fuerza numérica solo desde 1990. Cuando se subrayan flujos anteriores, están acotados a aldeas muy específicas, con un peso más simbólico que real (cfr. Beltrán, 2003: 33 y 41-42). Como sea, la emigración transoceánica en la actualidad es considerada una prestigiosa aventura, en un marco que valora más el riesgo personal que la seguridad. El emprender un riesgo (xia hai, 下海), lanzarse a un "mar" incierto pero lleno de promesas, sustenta en buena medida el deseo local.

De manera similar, en la zona se vive la exaltación de un sujeto ideal encarnado en el getihu (个体户), pequeño empresario con licencia de trabajo independiente ${ }^{13}$. De hecho, en la provincia de Zhejiang se asignaron las primeras autorizaciones en toda China para crear pequeñas empresas privadas, en un comienzo familiares y luego más extensas. Este modelo impulsado por el Estado encontró un eco potente en estructuras culturales locales basadas en relaciones de parentesco. Wenzhou además fue una de las primeras ciudades con economía de mercado en China. Incluso en 1984 el gobierno de la República Popular China (en adelante RPC) la proclamó entre las 14 Ciudades costeras abiertas al exterior, catapultándola hacia un espectacular auge comercial. En la actualidad produce la mayoría de las marcas de prestigio de ropa y calzado del país y controla el mercado mundial de las griferías, los zapatos y los mecheros. Casi todos sus paisanos reiteran, muchos de ellos sin disimular su orgullo, que es la ciudad "más capitalista de China"14.

Los chinos de Qingtian y Wenzhou comparten en gran medida esas marcas de origen. Sin embargo, en el imaginario general de China - y también en el propio-, se sitúan en posiciones diferentes. Unos simbolizan el mundo rural y el pequeño comercio, marcado por una historia no muy lejana de vendedores ambulantes que

${ }^{12}$ Las cifras del Ministerio de Trabajo e Inmigración de España al 31 de diciembre del 2009 registran 4.791.232 de extranjeros con tarjeta de residencia en España. Los ciudadanos chinos son el sexto grupo más numeroso, con 151.547 personas, que representan el 3,1\% del total. El II Anuario de la Comunicación del Inmigrante, del mismo ministerio, reporta que un $70 \%$ proviene del cantón de Qingtian (Ministerio de Trabajo e Inmigración de España, 2010 y 2007, respectivamente). La conformación de tan potente dispositivo de producción de emigrantes en dicha zona ha sido documentada principalmente en Beltrán 1996 y 2003.

${ }^{13}$ El término getihu designa a una pequeña empresa y también a su propietario.

${ }^{14}$ Pese a que las once principales ciudades de Zhejiang figuran entre las treinta con mejor renta per cápita del país, se mantiene una marcada dicotomía entre el ingreso anual urbano y el rural. En el 2009 alcanzaba a los 3.600 dólares en las ciudades, duplicando con creces los 1.500 del mundo campesino. 
recorrían el país con sus mercancías. Los otros encarnan el proceso modernizador y capitalista, las clases medias empresariales y una emergente burguesía bohemia.

Siguiendo esa distinción, entre los qingtianeses de España se aprecia más reiteradamente una concepción de cara centrada en la importancia de liăn: el cumplimiento de la pauta de valores como generadora de "peso", de "nivel". Dicha pauta suele ser significada dentro de un canon de ayuda colectiva, de sostener ante los otros la imagen de un individuo "confiable". Esta "confianza" se actualiza al menos desde dos posiciones: por una parte implica el "derecho" a solicitar la ayuda de otra persona, de quien se espera el primer don, y por otra, el "derecho" del donador a esperar un acto de reciprocidad del demandante.

En el caso de los qingtianeses, se distinguen dos grandes tipos de "donadores". Uno asociado a la familia, ligado a la imagen tradicional del padre o la cabeza del linaje, y otro asociado al circuito extrafamiliar, donde se construyen los "verdaderos" sujetos de "peso". Tener liăn implica construir cara gracias a la entrega de dones leídos como bienestar colectivo: pagar de su bolsillo clases de español o de chino comunitarias, facilitar casas u otros espacios para tales actividades, otorgar préstamos en dinero en circuitos extrafamiliares, hacer donativos sin otro interés que su honra, donar tiempo de trabajo o asesorías para la instalación de algún recién llegado, etc.

Ya sea un don dentro o fuera del circuito parental, otorga cara al legitimarse - discursiva o prácticamente - más en el reparto comunitario que en la jerarquía de la deuda. Sin embargo, como resulta obvio y pese a que los chinos se esmeren en negarlo, el mismo acto instaura una superioridad no solo económica, sino social y moral que refuerza la autoridad del donador. Quien recibe lo dado acepta los términos de dicho acuerdo, cuya amplitud y contenidos dependerán solo de quienes lo reconocen y se benefician del mismo. Se trata, por lo mismo, de una relación de poder y respeto que se legitima a partir de acuerdos particulares.

A una autoridad así concebida se puede acudir — por ejemplo- con el fin de resolver problemas internos. Tal como señala un qingtianés: "Si alguien tiene un problema con otro, entonces esa persona puede buscar a alguien que tenga cara para resolver el conflicto. La persona con cara es alguien que todos respetan. Nadie dirá que no a la solución que él proponga. Si es una persona con liăn, honorable, es una persona con poder".

Esto abre la discusión hacia el amplísimo tema de las repercusiones de la lógica del don en la constitución de una autoridad legítima en el contexto de la modernización europea, basada en el imperio "universal" de la ley. Entre otros aspectos, en el caso mencionado no existiría mayor disyunción entre una autoridad políticojurídica y una económica, por ejemplo. La lógica presente en él estaría basada no en la abstracción de la ley, sino en relaciones concretas fundadas a su vez en el juego ambivalente de la solidaridad y de la lucha, del reparto igualitario y la competencia agonística, presentes en este tipo de lazo social ${ }^{15}$.

${ }^{15}$ Resulta aquí inevitable la "primitiva" comparación maussiana: "Un jefe no conserva su autoridad [...] más que si prueba que está embrujado y favorecido por los espíritus de la fortuna, 
Es innegable que este lazo particularista, pese a que suele ser leído como el núcleo de la inequidad y en ocasiones como la encarnación misma de la injusticia, configura también una red de dependencias que aseguran un orden, una estabilidad interna muchas veces paralela - no necesariamente opuesta - a la institucionalidad oficial local, con la cual puede o no mantener relaciones.

El punto es que tradicionalmente los qintianeses suelen asociar esa posición de poder a la "virtud". Como lo comenta otro paisano, miembro de la pequeña pero floreciente élite qingtianesa en Asturias, resaltando la contradicción entre el valor de mianzi y el de liăn:

Mianzi significa tener una posición muy alta. Entonces en un conflicto una persona que tiene mianzi tiene poder y puede negociar mejor. Todo el mundo le tiene respeto. Por ejemplo si tú eres gobernador o él es tu amigo, entonces lo que tú has dicho, todo el mundo debe hacerlo, tienes mianzi. Claro. Pero no basta con que una persona tenga dinero y poder, debe ser una persona con virtudes, que todos sepan que es honorable, que no busca su bienestar personal, es una persona con liăn.

La cita, sin embargo, además de iluminar la relación de la lógica económica con el poder político según lo piensa el mundo qingtianés, deja entreabierta la posibilidad de que esas vías que conducen a mianzi se reconozcan no solo por sus "virtudes" sino también por la investidura de un cargo público, es decir por su mera formalidad y apariencia.

Pero regresemos a la mecánica del don que opera en los citados ejemplos de mianzi. En ambos casos, el punto de partida está en la cadena de reciprocidades que emerge con el primer don. Alguien se siente con el derecho de apelar a una autoridad legítima según los criterios del grupo. En otras palabras, se "confía" en que alguien debe dar el primer don, el que es esperado o incluso exigido: en el primer ejemplo, hacer justicia, pero bien podría ser una ayuda en el plano económico, laboral o incluso en el privado familiar.

Como contrapartida, el donador a su vez deposita "confianza" en el que recibe. Espera de él un comportamiento adecuado a las normas de la reciprocidad según el nivel en que se encuentre. Es decir, también debe comportarse "virtuosamente", cumpliendo los deberes sociales adscritos a su posición. Si es dentro de la familia, por ejemplo, se enfatiza que la primera "donación" en dinero nunca se hace con ánimo de retribución, sino porque quien la entrega tiene liăn y porque todos operan dentro del yì (义, rectitud, justicia). Lo tácito, sin duda, es que la persona que recibe sí debe "devolver" el don primero o al menos esforzarse por hacerlo, demostrando un comportamiento laboral adecuado. De lo contrario pierde cara, como señala un informante: "Si veo que alguien pasa todo el día en las máquinas tragaperras, o no trabaja, no le prestaré dinero nuevamente, aunque sea de la familia. Por lo general esa gente no tiene cara, aunque está tratando de formársela".

que es poseído por ella y que él la posee; y no puede probar esa fortuna más que gastándola, distribuyéndola, humillando a los otros, poniéndolos 'a la sombra de su nombre"” (Mauss, 2008: 206). 
Algo similar ocurre con las personas que obtienen dinero "de mala manera", por medio de engaños bastante alejados del armonioso yi:

Alguien puede tener mucho dinero pero si la comunidad se entera de que es mal dinero, pierde cara. Si no tiene cara, deberá esforzarse por ganarla.

Un mafioso, por ejemplo, también trata de ganar cara, mostrándose como hombre con liăn, como hombre de peso. Puede que la comunidad no se entere de que es un mafioso, pero si se entera, esa persona pierde su cara ante los demás.

La apelación a la cara como liăn explica, por ejemplo, la posibilidad que tendrían todos los jóvenes para empezar a construirla aún sin tener dinero, siguiendo un parámetro tradicional de respeto familiar y valoración social de sus méritos. Sin embargo, la obtención de un capital monetario inicial es considerada una pieza clave para comenzar a construir y acumular cara:

Aunque no tenga nada, no tenga dinero, un joven puede llegar a tener cara si es correcto, si tiene yì; si ayuda a otra persona, por ejemplo, tiene y está ganando cara. (...) Un joven sin dinero puede empezar a construir cara si es buena persona. Si es esforzado y respetuoso con sus padres, con sus mayores, si ayuda a los demás. Entonces sus padres o los amigos de su padre podrán empezar a ayudarlo para construir cara, confiando en él para que instale su comercio, por ejemplo.

Tú vienes a pedir un favor a mí y yo te echo una mano. Por ejemplo te presto 500 euros, pero lo hago sin intención de esperar algo de vuelta. Entonces si tú mantienes yi dices: "Ese señor me hizo un favor y tengo que devolver ese favor"... y debes devolver el favor. Por ejemplo más adelante yo tengo problemas y tú estás mejorando, entonces tú me das una mano. Eso se llama yì. Pero es sin intención, es un gesto desinteresado. No es solamente devolver el dinero, es una forma de agradecer. En China normalmente, en su cultura, en su mentalidad, existe muy fuerte ese $y i$. Dar una mano sin intención...

Para construir cara se espera del otro un comportamiento acorde con su posición, lo que incluye el respeto de una legitimidad interna en la que el valor del dinero es considerado discursivamente solo en un segundo nivel, aunque no por eso menos importante.

En los qingtianeses, entonces, opera un dispositivo que conjuga los dos aspectos (liăn y mianzi), situando la primacía en el primero, considerado por algunos como un canon identitario que debe ser transmitido. En sus prácticas es perceptible la influencia de parámetros culturales confucianos que estimulan estructuras de reciprocidad asentadas en una particular concepción de las obligaciones y el valor social. Obviamente, la reproducción de sus extensas cadenas de acciones y relaciones será exitosa solo en la medida en que se puedan generar las condiciones que producen tales disposiciones. En otras palabras, habría que analizar cómo y qué se actualiza de tal dispositivo con raíces confucianas.

Me explico: pese a sus múltiples transformaciones históricas, el núcleo del confucianismo propone la búsqueda de una armonía que supone la práctica del ren (仁, 
bondad, humanidad, tolerancia) y de la piedad filial (孝, xiao), que conlleva deberes con los padres y ancestros. Tal armonía implica jerarquías en los roles sociales y en las obligaciones "debidas" a cada cual. Esta "bondad", por tanto, posee una dimensión naturalmente desigual, no-igualitaria: no se "debe" de igual manera a los padres, al clan o a los simples desconocidos. Todas las variantes del confucianismo coinciden en esa moral natural, de proximidad, con la mayoría de las sociedades tradicionales "que preexisten a los grandes sistemas universales: se trata de una ética de la retribución (bao), según la cual se devuelve mediante un comportamiento adaptado aquello que nos ha sido donado" (Zufferey, 2007: 79) ${ }^{16}$. Según este modelo, se debe enormemente a los padres, de ahí la importancia de la piedad filial. Se debe casi tanto al jefe o responsable de la sobrevivencia colectiva y se está menos en deuda con aquellos que no son parte del grupo.

Sin embargo, los qingtianeses insinúan también un trastocamiento, una puesta en suspenso de las leyes familiares de la buena fe y la "inocencia" del don armónico. Las leyes del cálculo, que se encontraban "culturalmente" controladas dentro de cada familia, se han ido afirmando progresivamente. La economía doméstica, que tradicionalmente administraba los asuntos económicos según el parentesco y la cercanía, está dando paso a un modelo otro, en el cual las relaciones económicas condicionan en un grado cada vez mayor las relaciones "debidas" al parentesco.

Estas familias chinas inmigrantes, tanto por las pautas internalizadas en origen como por aquellas derivadas de la ideología dominante en la sociedad de llegada, se encuentran sometidas a dos tipos de tensiones: las fuerzas de la economía y las fuerzas de la necesidad de cohesión interna. Pero no se trata de una dicotomía absoluta, pues la constitución de la economía como subsistema autorreferente y autónomo, es decir la "economía en tanto economía" se observa en paralelo con la continuidad o la constitución "negativa" de islotes de economía precapitalista que se perpetúan en el universo de la economía como ta ${ }^{17}$.

Si bien los chinos intentan distinguir entre las obligaciones asociadas a la familia y aquellas asociadas a criterios de utilidad o empresa, dicha separación opera solo en términos simbólicos, pues se encuentran en serios aprietos para deslindarlas en la

${ }^{16}$ Pese a sus variadas e incluso contradictorias versiones, todos los "confucianismos" presentan en común el ideal de armonía (he), que implica un rígido respeto a las jerarquías sociales: "armonía entre el cielo y el soberano (...); armonía entre el príncipe y sus súbditos; armonía en el seno de la familia, gracias a los ritos especialmente, que expresan los lazos y lealtades en la comunidad; armonía con sí mismo, gracias al perfeccionamiento moral y al estudio, lo que permite a cada uno encontrar su lugar en el orden natural y en el orden social" (Zufferey, 2007: 78).

${ }^{17}$ No es mi intención redundar en un tema abordado desde múltiples voces en el último siglo. Quizás solo destacar la de Bourdieu: "Este proceso corresponde a la emergencia de un campo, de un espacio de juego, lugar de juego de un tipo nuevo, cuyo principio es la ley del interés material" (Bourdieu, 1997: 175). Y la de Dumont en Homo aequalis (1977), remarcando esta autonomización del campo económico como característica de la modernización occidental: "[después de haberse separado de la política] lo económico se había emancipado también de la moralidad" (p. 46). "En el sistema económico (...) cada sujeto define su conducta por referencia solo a su interés propio" (p. 98); "el sujeto humano particular está emancipado de las coacciones morales" (p. 101). 
práctica. Un aspecto clave para explicar esta dificultad deriva de que - salvo raras excepciones - cada sujeto se encuentra inserto precisamente en empresas familiares que funcionan en un espacio transnacional. Es decir, en estructuras sociales que funcionan en un campo de relaciones capitalista basado en la maximización del lucro. Entonces cada familia necesariamente comporta en su seno diferentes lógicas de reciprocidad, con legitimidades contradictorias y no por eso menos aceptadas, las que tensan el espacio de quienes viven en ellas. Sin duda dichas confrontaciones operan, generando pugnas y fracturas. Como lo destaca un informante al comentar la cada vez más común fuente de conflictos dentro de las familias:

Hay peleas entre familias por dinero. Si es por dinero, la gente se pelea. Se pelean por interés. Entonces el antiguo honor ya no vale tanto. Anda y pregunta cuál es la principal causa de conflictos en las familias, de Qingtian, de Wenzhou, de donde sea... es el dinero. Préstamos no pagados, familiares que reciben ayuda y luego desaparecen (...). Todos están con problemas internos, pero nadie lo va a reconocer porque tienen que aparentar que sus familias son un ejemplo de virtud.

Se trata de un "peligro" que pone a prueba la fuerza de las obligaciones familiares. Si bien en ningún caso es posible proclamar la disolución de ellas, sin duda es constatable su tendencia a la laxitud, al menos en este aspecto relacionado con las ganancias y el lucro. Como la expresión más evidente de la hibridación de paradigmas y más concretamente del cambio que se vive en la familia-empresa transnacional, es frecuente encontrar padres que venden a sus hijos el patrimonio familiar, o el derecho a heredarlo, lo cual antes era impensable. Así lo narra un qingtianés:

Este restaurant es mío. Me lo vendió mi padre. Nos asociamos con mi hermano y se lo compramos a plazo. Terminamos de pagárselo hace 3 años, después de varios años de trabajo, pero el negocio pasó a ser nuestro. Ahora mi hermano abrió otro restaurant y yo le compré su parte en éste. Este restaurant ahora es mío.

Las antiguas relaciones clausuradas en el ámbito de la familia son cuestionadas por las nuevas generaciones y en general, tienden a retroceder. El discurso crítico a la antigua norma tradicional se expresa a partir de criterios de eficiencia, apelando a la necesidad de entablar relaciones (guānxi) utilitarias y pragmáticas como base de productividad, pero también como base de un nuevo tipo de confianzas. En otras palabras, son las familias que han logrado abrirse a las confianzas fuera de la red parental las que ostensiblemente muestran un mayor éxito económico y por lo tanto un mayor mianzi. En ese sentido, el siguiente comentario de un profesional autónomo suena lapidario al comentar las dificultades de algunos qingtianeses:

¿Empresarios exitosos?... ¡Qué va! (...) Tendrán uno o dos pequeños comercios. Los traspasarán o venderán a sus hijos, ¿pero mediano o gran capital?... ¡Nunca! (...) Está claro, tío. Si primera generación siempre es así... Tú ves muchas tiendas chinas, pero cada tienda es una familia. Yo nunca veo que un chino tenga diez tiendas. Cada chino tiene una tienda porque no tiene capacidad para organizar ni mantener más que eso. Solo una. 
Sus palabras, por cierto, no son aplicables a todo el universo de Qingtian, pero sí dan cuenta del tipo de "confianza" que funda el lazo social de la mayoría de los pequeños comerciantes. No obstante, un ejemplo de la profundidad y rapidez del cambio es el fuerte posicionamiento de una élite de Qingtian que en Madrid - por ejemplo - ha logrado el control del grueso de las importaciones de productos chinos y ostenta un lugar envidiable en las exportaciones españolas hacia la RPC. Incluso en 2010 un qingtianés ingresó al directorio de la Cámara de Comercio de esta ciudad ${ }^{18}$.

Entre los inmigrantes de Wenzhou, por su parte, este tránsito hacia las confianzas extrafamiliares resulta más evidente, en especial entre quienes detentan la posición de empresarios. Sin mayores complicaciones con liăn, aparece en ellos una potente homologación de cara con mianzi. El énfasis suelen situarlo en los componentes asociados al estatus, a la búsqueda de una posición económica alta, conceptualizada como ideal social ${ }^{19}$.

Mianzi es lo más importante, nadie quiere ser pobre, todo lo contrario. Los chinos quieren tener dinero, dinero para tener cara. Por eso hacemos negocio, por eso estamos acá... construyendo cara, quien diga que no, está mintiendo.

Ganar cara, tener mianzi... es un vicio. Todos estamos construyéndola, nadie se escapa de eso, si no tienes mianzi, no eres nadie. Es verdad que el dinero no tiene valor por sí solo, que se debe equilibrar con la rectitud. Pero sin él, no es posible hacer nada. No puedes tener cara, ni ayudar a nadie si no tienes dinero.

Aunque en algunos casos los wenzhouneses mantienen la distinción entre los dos aspectos de cara, sus discursos denotan un notorio avance de mianzi en su fachada más económica, en desmedro de las antiguas profundidades del liăn. Este último es mencionado en pocas ocasiones, mas de inmediato se reconoce que no siempre opera en las prácticas del grupo.

Con independencia de su origen territorial, la homologación directa de cara con mianzi es fácilmente identificable en los grupos empresariales más exitosos. $\mathrm{Al}$ margen de su reconocimiento discursivo, y más allá del circuito empresarial, la tendencia al consumo individual como representación ritual de poder, su ostentación, permea en mayor o menor medida a todos los segmentos sociales del mundo chino, en especial a las generaciones más jóvenes. Todos ellos identificarían la cara como mianzi, según explica un qingtianés de 28 años:

${ }^{18}$ Se trata de Hong Guang Yu Gao, 40 años de edad, 24 en España. Es dueño, entre otras, de una empresa de muebles y de una exportadora de vinos a China. Es miembro de la FEDECAM -Federación de Empresarios de Madrid — y de ACHE — Asociación de Chinos de España, que congrega a la élite de la RPC-.

${ }_{19}$ Se podría, a partir de esto, plantear alguna relación con los postulados de Earley, al menos en su propuesta relacionada con que la primacía de liăn suele darse en las comunidades chinas que mantienen algún sustrato de "colectivismo", a diferencia de las que se encuentran más inmersas en "parámetros societales", donde primaría la cara como mianzi (Earley, 1997: 133). Tal diferenciación se hace, como veremos, sin duda insuficiente. 
Mis padres me decían que ahorre, que ahorre, que si puedo ahorrar todo, pues que lo haga. Eso está cambiando muy rápido. Los jóvenes estamos más abiertos al consumo, queremos probar cosas nuevas. Por qué no, si a todos nos gusta cierta comida, si a todos nos gusta cierto coche, cierta comodidad en la casa... El mundo actual es una gran mezcla. Todos conocemos qué hay de bueno en cada parte y queremos cogerlo. Yo no sé cómo van a pensar mis hijos, pero sí sé que serán muy diferentes a mí y más diferentes todavía a mis padres.

Se vislumbra aquí, literalmente, la práctica cultural tradicional del ahorro ascético como base necesaria para la irrupción de nuevas pautas de prestigio, cuyo detonante se encuentra en la exhibición del consumo. Lo refrendan los chinos de Wenzhou, como el siguiente getihu de 30 años: "Los chinos son todos iguales, nadie quiere gastar en nada, pero cuando gastan, es para tener cara, mianzi. Ahí no importa mucho el gasto. Eso quiere decir que ya tienen dinero suficiente para hacerlo... Quieren lucirlo".

O tal como se queja un macaense al describir ciertos hábitos laborales de sus compatriotas, quienes vivirían una verdadera "obsesión" colectiva por acumular dinero para luego lucir su mianzi:

Los jóvenes un poco mejor... Un poco mejor que sus padres. Pero los chinos en general no salen a tomar un café, no van por aquí o por allá, ni (a) jugar en lugar público. Ellos solo en su casa o sentados en la caja. Ahí, para no gastar... no quieren gastar. Yo les digo "Joder, tío, si vale un euro". Y ellos: "No, si vale un euro, es mucho dinero...". Mira aquí a tu alrededor, ves algún chino en este café... ¡Yo no veo ninguno! Todos están currando. Y a la hora que sea siempre es lo mismo.

Se percibe entonces un cambio en las nuevas generaciones que puede ser leído no solo como el paso de relaciones comunitarias a societarias, sino como el ingreso del antiguo repertorio de legitimidades en un espacio social abierto a nuevas relaciones y consumos. Un espacio también agonístico, donde la cara se adquiere de manera ineludible a partir de relaciones de mercado, un espacio que también demanda acumulación y derroche de capital en la lucha por demostrarla. Eso podría explicar el énfasis de los chinos de ambas zonas en potenciar las "oportunidades", el desarrollo de las "capacidades" y el multilingüismo que esperan, por ejemplo, para sus hijos ${ }^{20}$. Así lo expresa, por ejemplo, un emprendedor de Wenzhou cuyo hijo de 7 años también habla inglés:

Los hijos de nosotros ya van a ser todavía más diferentes. Los que nacen acá serán españoles, pero sabrán hablar chino, esa será una diferencia con la gente de acá. Por eso tendrán más oportunidades que los españoles. Tenemos vínculos con otros países y mis hijos tendrán aún más. Vivirán un mundo más duro, con más exigencias, pero tendrán también más oportunidades y capacidades que otros porque sabrán manejar mejor el dinero, cómo hacerlo.

Y lo reafirma otro wenzhounés:

${ }^{20}$ La mayoría de los chinos de España son parejas jóvenes, en torno a los 30 años de edad. 
La mentalidad de los viejos es muy estrecha, solo tienen un objetivo en la vida: los hijos y la familia. Nosotros, los jóvenes, vemos otras posibilidades, queremos aprovechar las oportunidades y lo que se nos ofrece. Tenemos más mundo y conocemos más. (...) Si algo se te pone enfrente (...) hay que aprovecharlo. Hay que vivir según las capacidades de cada cual, cada persona aprovecha según sus capacidades $\mathrm{y}$ hay que ponerlas a prueba.

En ese marco de cambios, es necesario detenerse un momento en las diferencias que se aprecian en las legitimidades sociales asociadas al gasto y al don. Todo parece indicar que la característica introyección del sacrificio, considerada una de las bases de la modernización occidental, en tanto permite el fin del gasto entendido como quema comunitaria de la acumulación del excedente y posibilita el "ahorro ascético" individual, ensamblaría en algún punto con el valor chino tradicional que destaca el ideal de austeridad y ahorro, reconocido desde tiempos de Confucio ${ }^{21}$.

Como se lee en las mismísimas Analectas ${ }^{22}$ predicadas por Confucio en el siglo VI a.C. y recopiladas escrituralmente al menos desde el siglo III a.C.: "La opulencia puede conducir a la arrogancia, y la frugalidad a la tacañería. Es preferible ser tacaños que arrogantes" (7.36). Sin embargo, pese a los múltiples ejemplos de estímulo a la vida frugal y al ahorro como expresión de equilibrio, éste último no se entiende sin una predisposición a cultivar públicamente mianzi. Por dar algún ejemplo, en Analectas 8.13, el propio Confucio alecciona: “...Brillad en un mundo que sigue la Vía; ocultaos cuando el mundo la pierde. En un país en el que prevalece la Vía es vergonzoso permanecer pobre y anónimo; en un país que ha perdido la Vía, es vergonzoso convertirse en alguien rico y recibir honores" (Confucio, 1998). A fin de cuentas, como era de esperar, aunque la prédica redunda en la necesaria moralidad de mianzi - es decir su cara liăn - la vida social no se entiende sin prestigio y reconocimiento económico.

Si bien los criterios de acumulación (ahorro) podrían encontrar algunos parámetros comunes con la modernización occidental, aunque originados en diferentes procesos históricos, la tensión se haría evidente en los criterios que legitiman el gasto. La tendencia a la aceptación del orden mundano y al desarrollo de técnicas para insertarse en él comienza aquí a tomar nuevos giros. La "apertura" al consumo, en su tensión modernizante, permite la continuidad de dos tipos de gasto que coexisten en sus prácticas sociales: el gasto "colectivo" y el gasto "individual", ambos históricamente ritualizados y con un fuerte carácter agonístico. Las condiciones de producción de estas disposiciones pueden rastrearse incluso en referencias muy anteriores al ingreso en los patrones de racionalidad moderna. En las mismas Analectas, por ejemplo, se encuentran alusiones a ambos gastos. Convocando de forma directa la acumulación individual ostentatoria, se lee en el 4.5: "El maestro dijo: ser

${ }^{21}$ Tal modelo virtuoso, valga la puntualización, muestra continuidad con ideales bastante anteriores, identificables al comienzo de la dinastía Zhou Occidental — siglo XI al 771 a.C.—- es decir cinco siglos antes del propio Confucio. El mismo Maestro reconoce "adherir plenamente a los Zhou" y agrega que él "no ha inventado nada" (Zufferey, 2007: 77-78).

${ }^{22}$ El título original, Lún Yǔ, significa "Discusiones sobre las palabras". Los destacados son míos. 
rico y tener rango es algo que todo el mundo codicia". O bien en el 8.16, estimulando el gasto ritual colectivo asociado a mianzi:

No puedo encontrar defecto alguno en Yu. Comía y bebía frugalmente, pero mostraba una absoluta devoción en sus sacrificios a los espíritus; se vestía pobremente, pero sus túnicas ceremoniales eran magníficas; su morada era modesta, pero empleó su energía en canalizar las inundaciones. No puedo encontrar defecto alguno en Yu (Confucio, 1998).

No es necesario hurgar demasiado para encontrar equivalencias con la actual disposición a lucir la "túnica ceremonial" en el momento de las "donaciones" de los hombres poderosos que hoy funcionan "como dioses" — parafraseando a Mauss ya sea en la institucionalidad de alguna organización étnica, en el reparto solidario en la privacidad de su grupo o en la búsqueda de reconocimiento en general en cada uno de sus espacios sociales.

El "gasto colectivo" se puede leer anclado en prácticas de representación agonística tradicionales, generalmente entre familias que demuestran sus respectivas posiciones a través de los bienes "ofrecidos", por ejemplo, en una comida retribuible, o bien en el "gasto" ostentado por las "cabezas" de la comunidad en la fiesta oficial del Año Nuevo Chino, en un derroche representado por las elites asociativas ${ }^{23}$.

Sin omitir la profundidad histórica de esta disposición, la entrada al espacio de la modernidad ha tendido a reforzar otros patrones asociados a mianzi, ligados a un proceso de monetarización de las relaciones. Un ejemplo se aprecia en la creciente relevancia que adquiere ante los ojos del grupo, en un primer nivel, el "gasto individual" frente al tradicional "gasto colectivo". Más aún, se tiende a reforzar el aspecto personalizante de este último, reestructurando las jerarquías individuales y las lealtades dentro de cada grupo.

El tema se complejiza al asumir la hipótesis de una creciente identidad reflexiva al ingresar en la sociedad moderna. De ser así, el vínculo societario, en tanto lazo voluntario no implicaría solo la búsqueda de eficiencia racional, sino también el reconocimiento de cada individuo "como actor personal a la vez que social" (Dubar, 2002: 221-222). En coincidencia con el caso analizado, las "acciones colectivas" al ingresar en la esfera del consumo no estarían atrapadas en un puro economicismo, entendido como una elección racional para satisfacer una demanda, sino que res-

${ }^{23}$ En "La noción de gasto", George Bataille introduce en el orden económico la inevitable presencia de la actividad inútil, excedentaria, presente en todo sistema humano. A los clásicos criterios económicos "restringidos", basados en la escasez, la conservación y la ganancia, contrapone los propios de una "economía general", preocupada de administrar el derroche, la exuberancia, el excedente. En una sociedad mercantil, el ceder mercancía sin esperar retribución monetaria suele ser interpretado una pérdida, una destrucción. Al contrario, Bataille constata que la sociedad actual produce un "molesto" excedente, que debe ser destruido, induciendo al sacrificio, en una destrucción de bienes que no están mediatizados por el funcionamiento del capital (Bataille, 1987: 23-43 [1933]). En ese sentido, la tradicional escena del "potlach chino", la quema festiva que agonísticamente constituye a sus élites, encuentra una veta no menor en el consumo como derroche ostentatorio. 
ponderían a un reconocimiento de identidades "electivamente" conformadas, pero siguiendo una lógica irracional basada en el derroche no utilitario ni productivo.

De esta manera, en coexistencia con esas prácticas "colectivas" ingresa el patrón de consumo "individual". Un gasto - claro está- nunca concebido fuera de la construcción social de la cara. Al contrario, esta nueva "quema individual de excedentes" sirve para construir mianzi, para representar una posición en la lucha por la jerarquía según una lógica agonística que da cuenta de la doble articulación de mianzi, individual y colectiva.

En la ostentación individual de la posición, la escala del prestigio viene dada por los parámetros de mercado, envistiendo de valor nuevos objetos que ingresan en el repertorio simbólico asociado a mianzi. Resulta evidente que esta última construcción agonística no difiere mayormente, en este aspecto, de los patrones de la distinción de una sociedad capitalista: más bien se ha engarzado en ellos. Incluso se aprecia en ciertas "élites empresariales" la necesidad de nuevas distinciones al constatar el desgaste simbólico de algunos objetos por la masificación "excesiva" en la comunidad:

Los coches, la ropa, aunque no se diga, uno está siempre mirando, viendo, qué tiene el chino de al lado. Cuando tiene cara, un chino siempre quiere distinguirse. Por ejemplo, yo creo que uno debe andar siempre bien vestido, cuidarse. Creo que los chinos debiéramos andar siempre bien vestidos... sé que no es así en todos... Hay ropa que yo no usaría, o que no le compraría a mi esposa. Ella también debe lucir bien, entonces no vamos a comprar ropa en un bazar barato de Todo a Cien.

Uno ve cosas que hace un tiempo te daban caché, y de pronto empiezan a parecer de mal gusto. Si quieres mianzi, hay que saber donde elegir. No se trata de ser frívolo, de tener vacío (sic), sino de querer mostrar la prosperidad. El chino busca ser especial, original, entonces, si puede, no compra cualquier cosa.

El patrón de la nueva distinción, necesaria debido a la contaminación simbólica del objeto, nuevamente está dado por la oferta del mercado, el cual si bien "democratiza" a partir de la posibilidad de consumo, en un gesto paralelo da respuesta a la necesidad de distinguirse, posibilitando la diferenciación social a partir de un nuevo nicho para consumo más exclusivo.

En ambos ejemplos de gasto excedentario, destaca el rol que le cabe a la triangulación de un Otro en la conformación de la autoridad interna. En el primer caso - gasto ritual comunitario-, los representantes de la élite china obtienen legitimidad por dos vías: el reconocimiento de las autoridades locales españolas y las vinculaciones con grandes empresas transnacionales. Dichos vínculos - guānxipor lo general son expuestos en cada uno de sus ritos públicos. Por medio de ese reconocimiento se ratifica o no su posición intraétnica. El segundo caso - el rito individual - requiere de una menor exposición del vínculo "político" o del guānxi económico, pero sí contempla un robusto ingreso en los parámetros de consumo, donde una escala de generación del valor viene determinada por el mercado. 
Todos están buscando tener cara, solo por aparentar. Un tío el otro día se compró un coche carísimo, solo por la cara. Yo le decía: "Pero tío, si eso te va a sobrepasar, no te da la vida para eso". "Es que debo tener cara - me decía- ¿Cómo no voy a tener cara?". Y ahora lo ves y solo dice: “Tengo que pagar, pagar, pagar”. ¡Y joder, tío!, si después se anda quejando de que todo está tan caro.

En este tránsito es posible observar un proceso de fetichización de objetos prestigiosos ${ }^{24}$. No se trata de una simple "preferencia" individual. Y no lo es pues no responde a una "necesidad" ni a una "elección" puramente particular ni racional. Es una construcción simbólica, grupal, que toma la forma de una internalizada disposición a ciertas marcas, como los teléfonos Nokia y los coches Mercedes Benz, verdaderos iconos del grupo. No es de interés acá analizar el detalle de la conformación de las tendencias de consumo, sino de constatar el peso relevante de la articulación en el mercado del antiguo valor de mianzi y sus transformaciones. Tal como narra un chino de Getafe, dueño de un restaurante:

Todos los chinos que conozco quieren un Mercedes Benz. Todos. Yo les pregunto por qué, que cuáles son las ventajas técnicas o lo especial del coche... pero nadie sabe. Es común verlos subiendo sacos con patatas o verduras al coche de lujo, que les ha costado 60 mil euros. Yo les pregunto ¿por qué mejor no te compras uno un poco más barato y con 3 mil euros te compras un utilitario? Pero no, ¡tiene que ser un Mercedes!

Ejemplos como el anterior, quizás menos extremos, son narrados no desprovistos de un toque de humor, pero siempre surgen a la hora de explicitar "la nueva escena" del mundo chino, donde en paralelo al ascetismo cotidiano proliferan gestos ostentatorios, por ejemplo las bodas lujosas, con los novios luciéndose en limusinas por el centro de Madrid u otras extravagancias "festivas" antes inconcebibles. La presión de mianzi explica la proliferación de este tipo de servicios matrimoniales. En el barrio de Usera, también en Madrid, donde vive una comunidad china relevante, en un espacio de un par de manzanas se concentra una variada gama de calidades y precios para esta demanda ${ }^{25}$.

${ }^{24}$ Desde Marx a Lacan se traza una extensa línea de análisis del rol de las triangulaciones y mediaciones. No se debe perder de vista que Marx fue el primero en proponer la fetichización como característica de la sociedad capitalista, en tanto cosifica las relaciones sociales. En la triangulación freudiana un objeto fetiche sería el sustituto simbólico del falo femenino (Freud, 2009: 116); recuérdese que Lacan define falo como el significante del deseo del Otro, lo que podría iluminar más de una versión de mianzi en la estructura del deseo social (Lacan, 1985: 285-290 y Lacan, 1990: 278).

${ }^{25}$ La concurrida hipótesis de Bell, al postular que la inequidad social expresada en los rituales jerárquicos de la vida cotidiana china, "contribuye" a la equidad económica, parece aquí perder algún sustento. Al ingresar en la lógica de reciprocidad de quienes la viven, la "equidad" económica que identificaría Bell no sería más que una muestra del "reparto solidario" propio del don, el cual también contiene en sí una lógica aristocrática y jerarquizante, generadora de deudas y "superioridades". Bell parece omitir que la desigualdad económica es un factor necesario para ratificar la jerarquía cotidiana (Cfr. Bell, 2008: 38 y ss.). 
Pese a las primeras distinciones entre liăn y mianzi, es evidente la tendencia a priorizar el componente mianzi como el que realmente opera en la construcción de la cara. Aunque está más presente en el discurso de los wenzhouneses, se trata de un elemento transversal reconocido explícita o tácitamente por todos los segmentos chinos. Lo explica con certeza un empresario de Rui' an:

El chino ya no está encerrado en su cultura, quiere saber del mundo. Quiere tener estatus, que lo vean, lucir lo que tiene. Sabemos que los españoles nos miran, que algunos tienen envidia, muchas veces no entienden cómo prosperamos tan rápido. Entre nosotros decimos... mira la cara que pusieron cuando me vieron con el coche nuevo. Eso generalmente no se dice, el chino oculta a veces los negocios que está haciendo para no despertar sospechas, para que no hablen mal. Pero llegado el momento siempre se luce, busca el caché.

Tal como sucede con la construcción de guānxi — relaciones-, mianzi genera tensiones y pugnas dentro del grupo, nuevos discursos circulantes, los que permiten dar cuenta de la existencia de diversas redes dentro del campo - siempre polivalente- en el que se ubican estos agentes en pugna por posicionarse en el espacio social y ser reconocidos a la vez como un otro legítimo ${ }^{26}$.

No pretendo reincidir en la ya extensa discusión relacionada con las bases del multiculturalismo y su ingente producción textual, pero me parece relevante, para insistir en algunos puntos de inserción de las lógicas del don en la modernidad y el mercado, subrayar lo que desde Hegel se considera el fundamento del orden social igualitario en occidente. Me refiero a la constatación del "deseo de reconocimiento" como un sustrato político moderno, lo cual, según me parece haber descrito, tiene un claro paralelo con las formas de construcción de mianzi en el mundo chino.

Como describe Kojève comentando a Hegel, el hombre "no se experimenta humano más que si arriesga su vida en función del deseo". En esa lucha de mi deseo con el deseo del otro, "yo quiero que él reconozca mi valor como su valor [...] Dicho de otra forma, todo deseo humano [...] es, a fin de cuentas, función del deseo del reconocimiento [...] Sin esta lucha a muerte por el prestigio, no habría jamás habido seres humanos sobre la tierra. En efecto, el ser humano no se constituye más que en función de un deseo que se refiere al deseo del otro, es decir - a fin de cuentas - de un deseo de reconocimiento" (Kojève, 1947: 14).

En otras palabras, los seres humanos solo se constituirían como sujetos al lograr el reconocimiento del otro, cuando esa imagen de sí mismo es revalidada por un otro.

${ }^{26}$ Otra transformación del antiguo criterio de reciprocidad se aprecia en algunas élites comerciales y organizaciones con fines de lucro, en las cuales tiende a establecerse una forma ritualizada de relaciones (guānxi), priorizando el contenido eminentemente pragmático, incluso utilitario de las mismas. Es lo que algunos chinos mencionan como guānxi-xue, desprovisto de gănqíng (感情, sentimientos, afecto) y de rénqing (人情, devolución del favor como obligación moral) del guānxi más tradicional. En la práctica, este cambio no ha implicado una menor profundidad en la cadena de deudas, pero sí ha contribuido a acortar los circuitos temporales de la "retribución", permitiendo tanto su cálculo monetario como la aplicación de represalias (contables o no) con un criterio igualmente pragmático y desprovisto de culpas "ancestrales". 
Hegel reconoce que los seres humanos se mueven "naturalmente" en la búsqueda del bienestar — como propone el pensamiento liberal clásico-, pero se alcanza la "plena humanidad" cuando incluso se arriesga la vida por "el deseo del deseo", por el reconocimiento de otra conciencia. En su extremo, Hegel plantea incluso que la verdadera libertad solo se experimenta en esa lucha por el reconocimiento.

Es difícil no poner este análisis en relación con lo recién descrito, referido a la forma de operar del don agonístico y la triangulación de las posiciones intraétnicas.

Al margen de las tensiones que genera o más bien explicando esta lucha, resulta innegable la existencia de elementos constitutivos comunes a todos los chinos, como verdaderas olas centrantes que arrastran hacia un mismo e inevitable punto, como si la ley de acumulación del capital simbólico en ocasiones tuviera una sola gran regla: "construir cara", "acumularla", "no perderla". Y esta única ley tuviera un único e incuestionado camino: acumular dinero para demostrar poder, ostentarlo. Como concluye drásticamente un informante de las jóvenes migraciones, quien comparte la apremiante necesidad de tener mianzi: "Dinero, simplemente el dinero, tener cara consiste en eso".

Mianzi contiene, por tanto, en su lado positivo y ostentable una analogía con el éxito económico. Pero en su anverso negativo, vergonzoso, comprende su par indisociable y oscuro: el fracaso. En el ejemplo más común, esta desgracia se refiere a la quiebra del negocio establecido o a la imposibilidad de instalarlo. Cuando eso ocurre, la deshonra ante el grupo es tal que los afectados simplemente huyen del lugar sin decir nada: han perdido la cara (shi mianzi, 失面子):

Claro, hay chinos a los que les va mal, chinos que fracasan en sus comercios. Cuando eso pasa, tú simplemente un día te enteras que se han ido (...). Un chino nunca dice: "Mi negocio está mal". Nunca. Siempre te van a decir que va bien. En cambio un español siempre te va a decir que su negocio va mal, que la crisis o lo que sea. Entonces un día los chinos ya no están más y todos se enteran que están en la bancarrota, que han cerrado su negocio de un día para otro y que se han ido a buscar suerte en otro sitio. Todo muy reservado, solo (lo) saben bien los más cercanos.

La necesidad de mantener la cara y mostrar siempre "lo mejor" de su familia y de sí mismos, los obliga a ocultar su situación real. Los chinos "fracasados" se retiran en silencio y buscan insertarse en otro lugar geográfico, dentro o fuera de España, apelando a sus redes transnacionales para "volver a empezar". Las deudas no pagadas generan un problema en ocasiones insalvable, que deriva en nuevos compromisos de pagos a futuro, poniendo en "garantía" su palabra basada en el respaldo de otros familiares o redes de amigos. "También están los casos de chinos que simplemente se van y dejan a todo el mundo con deudas impagas, pero son los menos, la mayoría quiere mantener la cara y por eso llega a nuevos acuerdos", acota otro informante. Como sea, siempre se trata de un hecho dramático.

Según explican, perder cara puede operar como diuliăn (王臉), en su marcado aspecto ético-moral, o shi mianzi (失面子), cuando es una pérdida de prestigio por cualquier causa, incluida la ética. La forma mei you mianzi (没有面子) señala no 
solo el acto de perderla, sino a quien no tiene o la ha perdido por completo. El ejemplo en cuestión podría ser nombrado por las tres, pero con más propiedad por las dos primeras ${ }^{27}$.

Resumiendo, el valor social otorgado a la necesidad de tener cara, entendida como mianzi, está potenciando la inserción en pautas que se han identificado como propias de la modernidad occidental, orientándose "racionalmente" a la búsqueda del lucro y el éxito económico, pero también a la lógica "irracional" del consumo y el derroche ostentatorio, en tanto dimensiones del reconocimiento social. La constatación de este tránsito, sin embargo, en ningún caso puede leerse como una absoluta novedad ni como una "transparente" integración en parámetros modernizantes. No es una novedad, pues la legitimación de muchas de sus prácticas encuentra una extensa profundidad histórica relacionada con la internalización de normas culturales confucianas, hoy resignificadas ${ }^{28}$. Tampoco es "transparente", pues si bien el movimiento agonístico de mianzi se ha visto potenciado, estimulando la competitividad y el consumo, su lógica se basa en acuerdos particularistas, distantes de la legitimidad política "igualitaria" y de la universalidad abstracta de la ley.

Hasta el momento he descrito un tránsito central de cara, mostrando algunas de las tensiones y luchas que provoca entre los actores inmersos en ella. Ensayaré a continuación detenerme en las principales instituciones configuradoras de las nuevas obligaciones de mianzi. Me centraré en los más relevantes núcleos definidos en "origen", cuyos contenidos y pautas encuentran una nada menor continuidad en las redes formadas en Europa y España, insertas en espacios sociales que estimulan disposiciones semejantes.

\section{El empresario-ru}

Sin duda existen prácticas relacionadas con el prestigio, y entre ellas, constituyendo una especie de imaginario del éxito, resalta el ideal de ser empresario como un vector transversal a todos los segmentos chinos. Ser empresario da mianzi, a diferencia del trabajo dependiente, y aún más allá, del ser obrero. En cada diálogo surge la distinción interna: "Yo prefiero ser libre, no como ellos que deben trabajar con horarios", me han comentado en más de una ocasión - muy ufanos - algunos getihu wenzhouneses al comparar su situación con los chinos que mantienen un trabajo asalariado. El imaginario del emprendedor se instaura como una prestigiosa forma de movilidad social basada en el "esfuerzo individual". Esta disposición en gran medida refleja un discurso ideológico legitimado en origen. Si bien es indudable que en la sociedad de llegada comienzan a constatarse nuevas lecturas y transformaciones, es relevante el diálogo y las resignificaciones de estos grupos con su

${ }^{27}$ Según Ho (1976: 876), en la cultura china siempre la vergüenza estaría asociada a la pérdida de liăn y no de mianzi. Los datos recogidos en España permiten tensionar esa propuesta, pues existe un correlato hegemónico entre vergüenza y pérdida de mianzi, independientemente del liăn, la honradez y decencia del afectado.

${ }^{28}$ Es necesario puntualizar que dicha internalización "confucianista" no se refiere a una esencia ni tampoco permite plantearse como única explicación causal, lo que no le resta peso como una de las principales instituciones configuradoras de las disposiciones observadas. 
tradición cultural, con sus institucionalizaciones de origen, las que aportan diferencia, según paso a describir ${ }^{29}$ :

Algunos autores intentan anclar esta dinámica empresarial de Zhejiang en un supuesto ethos de Wenzhou: la tradición "pragmatista" desarrollada hace unos 850 años, durante la Dinastía Song del Sur, a partir de los presupuestos de la escuela Yongjia - Wenzhou en ese tiempo-. Ella propugnaba un modelo de gobierno basado en el comercio y la agricultura, considerados base de la riqueza. Esta concepción difería de los principios confucianos que menospreciaban a los comerciantes, a quienes el Maestro situó en la escala más baja del prestigio social, en el lado opuesto a los sabios y burócratas. Contradecía también la rígida jerarquía social confuciana, que poco parece haber estimulado la iniciativa individual, salvo para "adaptarse al mundo", y que más bien consolidó durante siglos el poder de los funcionarios, quienes obstaculizaron la empresa privada en China. Es necesario entonces intentar comprender este vuelco, a primera vista bastante espectacular ${ }^{30}$.

Sin necesidad de aventurarse en el tiempo mítico local, es destacable —una vez más- que este ideal de construcción de cara no es en ningún caso disyuntivo con el discurso oficial del Partido Comunista Chino (PCCh), que impulsa el paso de la "virtuocracia" a la "meritocracia", es decir el valor del esfuerzo personal sobreponiéndose a las "virtudes ideológicas" que primaron durante la época maoísta (Hsu 2007: 82).

Este último punto es de relevancia pues en 1956 en Wenzhou - Yongjia—, en uno de estos vaivenes pragmáticos del régimen, en plena etapa de las "cooperativas avanzadas" se experimentó con un nuevo modelo de producción por medio de contratos con grupos domésticos individuales que explotaban la tierra de forma privada. Los llamados "huertos privados", pese a verse reducidos, se mantuvieron durante los momentos más radicales de la colectivización, como el Gran Salto Adelante y la Revolución Cultural (Beltrán, 2003: 25).

Con las reformas de Deng tomó fuerza un proceso general de descolectivización y en 1979 se comenzó a impulsar más ampliamente este modelo, llamado "Producción por Contratos de Responsabilidad Familiar". Fundamentalmente consistía en el desmantelamiento de las grandes cooperativas agrícolas sustentadas en el igualitarismo comunitario, traspasando el poder de decisión y la responsabilidad de la producción desde las unidades colectivas - como las comunas y brigadas - a los núcleos familiares, cuyos ingresos variarían en función del rendimiento. Cada

${ }^{29} \mathrm{Al}$ tratarse de una inmigración muy reciente, que además presenta un grado importante de relaciones sociales endogámicas, aún no es del todo observable la profundidad del cambio derivado de este impacto. Es ilusorio además pretender discernir con claridad cuánto de cierta tendencia modernizante en las relaciones de reciprocidad se debe a pautas adquiridas en China, en España, en la TV, internet o en otro "territorio" de sus tránsitos. Resulta significativo, sin embargo, que la distancia con algunas prácticas culturales tradicionales parece más aguda en los chinos recién llegados a España que en aquellos con más años de asentamiento. Quienes llevan más de 10 años en Europa, por ejemplo, tienden a mantener patrones bastante más rígidos según sus respectivas tradiciones locales, en comparación con los nuevos inmigrantes.

${ }^{30}$ A esta perspectiva de un ethos wenzhounés diferenciado de China se la ha llamado shigong хиеshuo —-teoría del pragmatismo-(Cai, 1999: 28-31). 
familia debía comprometerse con el Estado en determinada cuota de producción, la que era entregada a éste y el resto quedaba para su libre disposición, para ser comercializado en el sector privado, preferentemente en los "mercados de campesinos" (nongmao shichang) que abastecen a las ciudades. Es decir, el modo de producción pasaba a fundamentarse en una estructura cultural tradicional, la familia (jià), ahora catapultada mediante un contrato con el Estado a un nuevo rol en el desarrollo nacional. Las tierras seguían siendo del Estado, quien las entregaba por períodos de 30 años para la explotación familiar privada, pero en la práctica se liberalizó el sistema de producción y se obtuvo estadísticamente un mayor desarrollo agrícola. Esto movilizó la iniciativa personal de los campesinos, emancipando las fuerzas productivas rurales. Se habla incluso de un verdadero "síndrome de liberalización" a partir de este momento (Fernández, 1998; Shirk, 1993: 38).

El éxito del sistema en el nivel local llevó al Comité Central del PCCh a implementarlo en 1982 en el nivel nacional. Al año siguiente, las autoridades centrales - pletóricas de entusiasmo con las nuevas cifras - emitieron un documento afirmando que la producción por contrato familiar era "una grandiosa creación del campesinado chino bajo la dirección del Partido", un "nuevo desarrollo de la teoría de la cooperativización agrícola marxista en la práctica nacional" (PCCh, 1983).

En paralelo, como ya he señalado, fueron legalizadas las pequeñas empresas familiares urbanas, llamadas getihu, que comenzaron a visibilizarse como la forma más popular de empresariado. Para Deng Xiaoping se trataba de una medida pragmática que permitiría disminuir el desempleo y a la vez ofrecer pequeños servicios "de calidad" para elevar el nivel de vida en las ciudades. Sin embargo, el sistema no tardó en expandirse a gran parte de China.

En los hechos, se trataba simbólicamente del ascenso al nivel de modelo nacional de todos aquellos sujetos que habían actuado según ese patrón, que vinculaba el trabajo individual con el ingreso recibido. A partir de ese momento la provincia de Zhejiang pasó a ser un ejemplo para el país.

Ése es el nuevo aire que insufla a los huaqiao (华侨, migrantes internacionales) de esas zonas, exaltados por el cambio discursivo oficial que los ha hecho pasar en pocos años de parias a héroes nacionales. Con ese estímulo, la mayoría comienzan como trabajadores, pero tras algunos años de esfuerzo y ahorro, cumplen su meta de convertirse en empresarios: comienzan a "tener cara".

En este ideal del emprendedor, cobra más peso el mianzi obtenido por el esfuerzo individual, es decir, el aportado no por algún tipo de prescripción, por una posición heredada o por el traspaso sin más de bienes familiares. La adquisición de mianzi implica un verdadero y extenso rito de paso, con su consiguiente sacrificio personal. En ese proceso de acumulación, muchos trabajan en dos o más lugares durante el día, o se dedican a la venta callejera una vez que terminan su horario laboral en alguna tienda:

Yo llegué a Madrid a trabajar con un amigo, pero no me gustaba estar de trabajador. Como todos, quería ahorrar para montar mi propia empresa. Es el paso primero 
[trabajar para alguien], de lo contrario de dónde sacas el capital. Pero nadie quiere estar en eso toda la vida.

Yo trabajaba vendiendo CD’s en la calle. Así empecé. El resto del tiempo trabajaba sirviendo en un restaurante, ayudaba en la cocina. Pero los chinos queremos tener cara, y estamos poco a poco juntando dinero para eso. Así, poco a poco, con trabajo, hasta que tienes el dinero y la ayuda para tu negocio propio.

Porque nosotros, nuestra educación siempre es Confucio. En mi generación está muy integrado, muy atravesado por la educación de Confucio. Normalmente aquí la gente todo lo ha obtenido por trabajo, por su esfuerzo. (...) En Europa, mucho trabajo por vivir. Luchando, luchando por años, ahorrando, trabajando sin descanso. Y luego poco a poco mejorando.

Se trata de un pasaje necesariamente individual, pero no solitario. Siempre se está plenamente consciente de la pertenencia a cierto grupo, de la fuerza o problemas de la familia, de la extensa red de reciprocidades que está en juego, así como de sus respectivos límites.

Pero dentro de lo posible, interesa deslindar los mecanismos que generan tal disposición. Y aquí, ineludiblemente, emergen al menos dos grandes aparatos altamente entrelazados durante siglos y a la vez en constante movimiento: el del Estado y el religioso, dando forma a las legitimidades internalizadas del nuevo campo económico en la familia transnacional.

Como resulta evidente, las pautas ético-religiosas relacionadas con el confucianismo siguen manteniendo un lugar destacado en la actualidad. Entre ellas, especial vigor cobra un principio confuciano que suele ser olvidado en occidente, en especial cuando se alzan las voces contra la supuesta falta de libertad del sujeto chino, aparentemente atrapado en una absoluta prescripción social. Me refiero a la igualdad fundamental que la ética confuciana confiere a todos los hombres. Según este principio, lo determinante para obtener una posición social no viene dado por el origen, por el nacimiento, sino por la educación. Todos tienen la posibilidad de cultivarse, con independencia de la calidad de su cuna, según sus capacidades, para llegar al ideal de un sujeto integrado a la vida social ${ }^{31}$.

Lo expuesto no resulta menor, pues las posibilidades y las exigencias sociales de cada cual no vienen dadas por las estrellas ni por divinidad alguna, lo que da forma a un sujeto enfocado explícitamente a la vida intramundana. A diferencia del cristianismo y todas sus confesiones, el dinero y el bienestar material, más que una

${ }^{31}$ Sin adscribir a los intentos fundamentalistas al estilo Li Zehou (Li, 1997) y seguidores, quienes pretenden demostrar la existencia de una identidad cultural china fosilizada en torno a la escuela rujia y por tanto al confucianismo, resulta innegable la permeación de las actuales prácticas sociales cotidianas por las pautas confucianas ya expuestas, objeto de variadas actualizaciones y versiones (Cfr. Makeham, 2008: 132y ss.; Bell, 2008). Una premisa esencialista similar levanta Yü Yingshi, argumentado que la ética confuciana explica el "triunfo" de la empresa comercial china nada menos que desde la dinastía Ming (1368-1644) hasta nuestros días (Yü, 1987). 
tentación son considerados entonces como el medio más importante para fomentar la moral (Weber, 1987: 429) ${ }^{32}$.

En esta moralidad intramundana de laicos, el ideal consiste en la adaptación del hombre al orden del mundo y sus normas. Para ello es necesario seguir sus códigos de corrección social y política. En ese sentido, fue un gran aliado que acompañó al Imperio desde sus orígenes, legitimando una especie de disciplina aristocrática, pero también, a su lado, un amplio espacio en el que primaba la "libertad" de múltiples posibilidades de acuerdos particularistas.

La propia ritualidad confuciana tiene como fin último el bienestar terrenal de quien la practica: una larga vida, hijos y riqueza, considerando solo muy lejanamente el deseo de honrar a los antepasados y en ningún sentido la búsqueda de un destino ultraterreno. Ante todo prima una actitud agnóstica y de rechazo a la posibilidad de una vida en otro mundo. Incluso cuando el confucianismo ha sido permeado por influencias "adivinatorias", "místicas" u observantes de un Más Allá (como es el caso del taoísmo o del budismo), siempre el supuesto destino ultraterreno se subordina a la posibilidad de manipular "espíritus" para que operen en el Más Acá. El propio Confucio rechazaba "vivir en lo escondido" y desacreditaba una vida de prodigios "para cosechar fama en generaciones venideras". Importa el aquí y el ahora (Weber, 1987: 427-428 y 438) . $^{33}$.

Sobre esa base, el ideal del "empresario" se corresponde con los nuevos énfasis dados al discurso confuciano. Se trata esta vez, en una más de las múltiples versiones del confucianismo, del estímulo oficial a la popularización y difusión de los valores y "virtudes" de la escuela rujia en la sociedad china contemporánea, específicamente para su aplicación en la lógica mercantil. Se levanta entonces como tipo ideal al "empresario confuciano", llamado empresario-ru o rushang, quien operaría según pautas de racionalidad económica propias del mercado — particularmente fuertes a partir de la década de 1990 - pero cumpliendo con ciertas virtudes confucianas como la honestidad y el compromiso cívico. Ante la constatación de la verdadera ola de empresarios que comenzó a emerger en China en esa década, muchos de ellos con pocos escrúpulos éticos, el propio Comité Central del PCCh el 2001 lanzó el Programa de Mejoramiento de la Moralidad Cívica, el cual contenía incluso una guía de comportamiento dirigida a este nuevo tipo de ciudadanos (Makeham, 2008: 323) ${ }^{34}$.

El explosivo aumento de los "hombres de negocios" ha pasado a protagonizar la escena social, jugando un rol central en la constitución de un nuevo modelo público. El discurso y las medidas estatales enfatizan con preocupación la necesidad

32 Esta característica, propia de la "ausencia de un dios supramundano" (Weber, 1987: 429) se encuentra en la base del discurso "ateo" del actual PCCh cuando rescata principios confucianos.

${ }^{33}$ Aparte del gran número de ateos y agnósticos, entre los chinos en España es común adscribir a varios credos a la vez. Ser indistintamente budista, taoísta, confuciano e incluso en no pocas ocasiones asiduo de ritos cristianos confirma otra característica de origen: el histórico poco peso de la institucionalidad religiosa en la vida cotidiana y en las familias, donde no es un asunto que genere presiones ni conflictos.

${ }^{34}$ Entre otras novedades, en ese documento se introduce oficialmente el concepto de ciudadanía en el discurso oficial del Estado en China. 
de dirigir a este empresariado no solo hacia el provecho y búsqueda de riqueza, sino hacia un comportamiento propio de un "caballero" - junzi-, es decir, un moderno rushang. Incluso durante la visita de Xi Jinping a España, el actual vicepresidente de China y hasta el momento más seguro sucesor de Hu Jintao fue presentado como un hombre éticamente intachable, que desde su posición de "Hijo de Príncipe" 35 gobernará contra la corrupción, enfatizando valores éticos tradicionales asociados al confucianismo. La prensa española subrayó este aspecto durante su visita en diciembre de 2010, lo cual sin duda no dejó indiferentes a los huaqiao.

Los chinos en España resaltan este compromiso que los empresarios deben tener con valores como la rectitud y el ser desinteresado, el ser generoso "con los suyos". Es decir, legitiman de una particular manera un "retorno" a las bases del don, ahora en el espacio capitalista:

Un empresario debe actuar con yì, todos los chinos deben actuar con yì. Por ejemplo, yo ayudo si alguien está mal, si necesita ayuda. Yo le paso dinero para que salga del problema. Todos los chinos lo hacemos, nos ayudamos entre nosotros. Pero no nos importa si ese dinero no regresa. Lo hacemos porque somos generosos. El chino cuando tiene yì es desinteresado. Luego, si el otro es correcto, sabe que tiene que devolver, pero no es una exigencia como un banco.

Estamos hablando que los chinos somos empresarios. Todos los de Zhejiang somos comerciantes. Somos buenos comerciantes, vemos dónde hay negocio.... Claro... Pero somos personas honestas, de confianza.

Si estás bien contigo, eres virtuoso, entonces puedes dirigir bien a tu familia, ser un ejemplo. Yo no puedo prohibir a mis hijas que beban alcohol si soy un borracho. Debo dar el ejemplo. Si estoy bien con la familia, entonces puedo dirigir bien lo que está fuera, estoy en equilibrio y el negocio va bien.

Pese a que existe una extensa producción académica que discute en torno a las características que debiera demostrar un rushang (Li Jian, 1997; Zhang, 2002; Makeham 2008, entre otros) se suelen subrayar algunas características comunes basadas en los valores "intelectuales" sostenidos por la escuela rujia: 1) la creencia en que todas las personas pueden comenzar a ser sabias a través del autocultivo moral, 2) la convicción certera de que tanto la motivación como la capacidad para alcanzar dicha sabiduría depende exclusivamente de cada uno y no está ligada a factores sociales externos, 3) un elevado sentido de la auto-reflexión, 4) la necesidad de desarrollar un elevado sentido de respeto hacia el otro y 5) la insistencia en que el sentido de la rectitud $-y i$ - invalida el beneficio personal $-l i-$.

Este último punto es relevante pues presenta obstáculos al beneficio capitalista individual. El confucianismo histórico inculcaría un compromiso básico con la "denigración" de tales beneficios, gesto entendido como vehículo del mejoramiento

${ }^{35}$ Dentro de la élite del PCCh suele distinguirse entre linajes de "Príncipes" o "Hijos de tenderos". Los primeros son descendientes de quienes participaron activamente en la Revolución y luego detentaron posiciones políticas y económicas de relevancia. 
moral. Precisamente es uno de los aspectos con más resistencias entre los getihu de España:

Es importante cómo te ven los demás chinos, entonces no todo es riqueza, mianzi y relaciones (guānxi), sino la imagen que tienen de ti... Si alguien no tiene justicia y rectitud $(y i)$, aunque tenga dinero y relaciones, pierde cara ante la comunidad y se va quedando más aislado.

Un empresario tiene mianzi, pero debe ser correcto, de lo contrario lo va perdiendo. Tiene valores, tiene ética, da confianza, no engaña, entonces es chino que aumenta mianzi.

Mis valores como empresario son parecidos a los de un padre. Cuido del bienestar de cada uno de los que forman parte de ella [la empresa], entregando según sus capacidades, pero nunca olvidando el total.

Me gustaría estar más tiempo con mis trabajadores, para conocer bien sus problemas y su forma de pensar. Un buen jefe es como un padre, la autoridad es así cuando hay respeto.

Busco el beneficio, me interesa el dinero, soy comerciante, pero siempre en equilibrio con la rectitud, con la responsabilidad y la justicia.

Operaría por lo tanto una disposición a legitimar la obtención de beneficios solo con la consiguiente obligación de reciprocidad, moral o material, de quien los usufructúa.

Dentro de este reiterado marco ético, es claramente reconocible un tipo de empresario que también se identifica en el ideal rushang, pero con un sentido bastante más pragmático, al defender la conducta ética como un valor monetarizable. Hacia ellos van dirigidas las campañas de difusión del gobierno de la RPC, posicionando la "ética rujia" en un rol insustituible en la construcción del socialismo de mercado, permeando las normas del mianzi entre los chinos de ultramar. Llama la atención la internalización de estas legitimidades en los getihu de España, quienes, por ejemplo, calculan monetariamente el beneficio que obtendrían por seguir estas pautas. Lo plantean, por supuesto, como la necesaria retribución a la honestidad social del comerciante:

El empresario que es transparente, que actúa con yì, que no espera simplemente la ganancia a cualquier costo, al final obtiene más beneficios, pues da confianza a los chinos, construye guānxi, y también gana más clientes. La honestidad da más ganancias por la confianza.

El empresario que no es honesto no puede mantener su empresa, pierde clientes y socios. Ya no le creemos. Hay algunos de mente estrecha que no entienden esto y buscan beneficio en corto plazo, incluso engañando, pero son pocos. Pierden dinero, pierden la inversión. Por eso el tema de la mala calidad de los productos ya no es así, eso está cambiando... a la larga es una inversión en la calidad. 
Las cualidades internas de una conducta moral son transformadas en una ganancia material externa. Tal como señalan los manuales de Estado que circulan entre los chinos analizando el fenómeno y promoviendo esta figura: "La moralidad no es algo despreciable, en tanto ella puede ser transformada en dinero. Algunas virtudes como la sinceridad, el mantener la palabra, la rectitud $-y i-$, pueden proteger la reputación de una compañía, atraer clientes y un staff de calidad, y por tanto genera considerables provechos para la compañía" (Wang, 2000: 2 y 3). En ese sentido, si bien resulta evidente que el confucianismo por sí solo no generó relaciones modernas ni capitalistas en China (Zurndorfer, 2004), todo indica que en algunos aspectos opera como un aliado respetable.

Los casos presentados dibujan esa figura. Se constatan asimismo los nuevos "equilibrios" basados en que ambas partes esperan una retribución utilitaria, que en última instancia siempre puede ser contabilizada en dinero.

Este tránsito se aprecia de por ejemplo en las redes guānxi basadas en familias, las cuales aún priman en los procesos de migración e inserción en la sociedad de llegada, articulando extensas cadenas de búsqueda y generación de empleos, cuyos líderes detentan la autoridad legitimada en su mianzi:

En China yo había trabajo (sic) pero muy difícil, ganar poco, muy poco, entonces difícil la vida. Yo veía a mis primos que habían emigrado, cómo mis primos salían, trabajando a Europa, regresaban con dinero. Entonces hablé con mi tío y salí yo también, a ayudar a mi tío. El me ofreció el sueldo, el pasaje lo descuenta de eso. Después trabajo duro para ahorrar dinero. Guardando, guardando el sueldo por años.

Conviene detenerse un momento en el análisis de las lógicas presentes en estas familias, entendidas como dispositivos migratorios en los cuales se tensan y mezclan la lógica del don y la lógica del capital. Si se lee desde la lógica del don, la relación dentro y entre familias contiene la ambivalente relación de solidaridad/ superioridad que le es propia. Como señalé, por un lado la relación de solidaridad aproxima a todas las partes, en la cercanía de quienes aprovechan el "reparto" de una ganancia. Por otro, implica una relación de superioridad que genera un movimiento de lejanía, al convertir en deudor a quien recibe, instaurando una jerarquía en cuya cima se encuentra el que dona (Mauss 2008: 161-165).

En el caso de las redes familiares de traslado e inserción de inmigrantes, la generación de la deuda original está impulsando más potentemente el movimiento de superioridad y jerarquía que el de solidaridad y cercanía. La estructura del don ha tendido a perpetuar las diferencias y aumentar la segmentación social del mundo chino inmigrante. Quien recibe un "don" se hace acreedor de una deuda que si bien es bienvenida en un primer momento, pues implica una ayuda significativa, puede convertirse luego en una extensa cadena de "sumisiones" de la cual es difícil omitirse $^{36}$.

${ }^{36}$ Que estas redes étnicas sean cuantitativamente la principal fuente de inserción, no constituye una diferencia con otros colectivos inmigrantes. Según estudios del Observatorio 
Veamos cómo funciona, desde un ejemplo, el patrón migratorio de la familia "emprendedora". Generalmente los integrantes de cada fragmento familiar arriban en momentos separados a España. Primero, y por partes, llegan los familiares directos del "emprendedor": esposa, hijos, padres, hermanos. En la medida que los recursos económicos se hacen menos escasos y a la vez aumenta la demanda por mano de obra dentro de la empresa familiar, comienza la "reagrupación" de los parientes cercanos. Ellos suelen provenir de ramas empobrecidas del árbol familiar. A su llegada a destino, pasan a formar parte de la mano de obra barata que ayuda a la expansión del negocio. En suma, suele ocurrir que la jerarquía familiar de origen no solo se replica en España, sino que tiende a perpetuarse.

En otras palabras, la lógica del don, más que un movimiento de cercanía, mantiene un equilibrio social a partir de la deuda entendida como distancia jerárquica. Entre ellos, sin duda, se ha "catapultado" la deuda en un nuevo espacio de relaciones que posibilita la maximización de su producto o excedente. La persona, familiar o no, ingresa en el círculo de su "cosificación" al ser comprendida como valor de cambio en tanto mano de obra.

Las siguientes narraciones de un joven de 20 años que vive y trabaja en la casa de su tío, en un restaurant, y de otro que ha visto el fracaso del negocio de su padre, iluminan este aspecto de las nuevas relaciones familiares:

Yo trabajo en el restaurant de mi tío. El me paga un salario, me da comida y una habitación. Como no tengo nada que hacer, después del trabajo me quedo con ellos en el restaurant; jugamos a las cartas o al májiàng. En la mesa se suman todos, menos mi tío, mientras descansamos él está ocupado de los negocios.

Mi padre ahora está en China, en Hankou, Qingtian. El había empezado un negocio en Italia y no le resultó, tuvo que regresar. Ahora él está negociando con mi primo para un préstamo. Quiere instalar un bazar en Gijón. Yo viajé porque mi primo necesitaba ayuda en el restaurant.

Pese a este ingreso al espacio de la "mercantilización", la nueva relación "capitalista" que marca el espacio familiar, en el que una parte pasa a ser el "empleador" y la otra "empleado", basada en la compra y venta de la mano de obra según criterios de mercado, tiende a ser explicada — en términos más simbólicos que realesocultando su carácter de dominación. De esta manera, aunque se trate de miembros subordinados de la estructura familiar, todos participan por igual en las fiestas y encuentros familiares colectivos. Este tipo de relación se aprecia en especial en las

Permanente de la Inmigración, dependiente del Ministerio de Trabajo de España, se trata de un punto común entre todos ellos (OPI, 2005: 86). Evidentemente, en términos cualitativos no puede permitirse una simplificación como esa, en tanto la estructura, relaciones, funcionamiento y valoración de las mismas no son equivalentes. No obstante, no deja de ser significativa la constatación estadística de que entre los senegaleses, marroquíes y ecuatorianos el recurso a parientes y amigos es incluso mayor que entre los chinos (OPI, 2005: 98). Esto podría explicarse en parte por la extensa circulación de prensa en chino especializada en avisos comerciales y de trabajo, ampliamente consultada por estos inmigrantes, que trasciende los límites de parentesco. 
pequeñas empresas familiares, en las que trabajan unas pocas personas, entre parientes directos y parientes "pobres". En la privacidad del hogar se mantiene el trato directo, cara a cara, compartiendo con distensión y confianza las relaciones cotidianas. Sin embargo, y en todo momento, cada uno sabe a la vez la posición jerárquica que ocupa.

\begin{abstract}
Todos vivíamos en la casa de mi primo. Estuvimos en la misma casa con su esposa e hijos hasta que llegaron más familiares. Entonces mi primo alquiló otro piso, donde empezamos a vivir los que no éramos de su familia directa, además de dos personas que llegaron y no eran de la jià — familia - En la casa, con él, primero comíamos todos juntos. El pagaba la comida. Después cambió, nos descontaba un poco por el alquiler y nosotros éramos responsables de nuestra comida. Pero seguimos siendo de la familia, no somos desconocidos, vamos a las fiestas familiares, allí vamos todos.
\end{abstract}

Los casos anteriores son prototípicos. Al interior de la jià, las relaciones se legitiman de manera ambivalente: se apela por una parte a la circularidad desinteresada del don, cuyo "excedente" beneficiaría a toda la familia, aportando al prestigio de todos. Sin embargo, dicho beneficio es apropiado por la parte dominante de la familia y en ningún caso su beneficio es redistribuido alcanzando todas las partes, al menos en su aspecto directamente monetario, de reparto de dineros. La acumulación del excedente, tanto en el caso del dueño del capital como en el caso del familiar que vende su mano de obra, opera en términos personales, como ahorro particular, de la misma forma que opera en términos personales la construcción del mianzi y la obligación de cultivar relaciones - guānxi-con el fin de obtener y acumular prestigio. En este esquema, cada vez cobran más valor las relaciones y el mianzi enfocado hacia fuera de la familia, valorados como una posibilidad rápida de acumulación de capital, acumulación que se instituye como el límite a partir del cual una parte de la familia - o un individuo dentro de ella - puede romper con su vinculación de dependencia. Sin embargo, siempre se mantendrá la subordinación simbólica entre las partes. Esto se aprecia, por ejemplo, en las posiciones de mayor o menor prestigio que ocupan en encuentros públicos, en las "representaciones" que les corresponde hacer o no en determinada ceremonia. Tal como comenta un chino de Qingtian al recordar la celebración del Año Nuevo Chino en Oviedo, el año 2008: "En el teatro están las autoridades españolas y los chinos con mianzi, pero no toda la familia. No, no toda. Sus caras visibles..., no sus trabajadores. Los que tienen cara, ellos están en los lugares importantes..."

Sin embargo, esta estructura objetiva no parece ser vivida con mayores contradicciones por parte de los "parientes pobres". Más bien se podría señalar la existencia de una doxa común, una sintonía entre las estructuras del habitus de los dominados y la estructura de la relación de dominación en la que se integran. Es decir, como una expresión de violencia simbólica, donde "el dominado percibe al dominante a través de unas categorías que la relación de dominación ha producido y que, debido a ello, son conformes a los intereses del dominante" (Bourdieu, 1997: 197). 
Todos ellos, quizás por lo mismo, en la cima de su imaginario anhelan convertirse, con mayor o menor esfuerzo, en empresarios-ru.

Por las razones expuestas, las estructuras de origen han marcado decisivamente a los chinos en España. El tipo de relación que se establece entre ellos, sus jerarquías simbólicas y en especial la posición que han pasado a ocupar en la sociedad de destino, dependen en gran medida del capital cultural que ya poseían antes de emigrar. El nuevo escenario que enfatiza la libertad y la posibilidad de construcción de un "proyecto" individual no siempre es suficiente para modificar las condicionantes sociales y económicas que los acompañan desde su origen: en revertir esa situación consiste, precisamente, el desafío acariciado por casi todos ellos.

\section{A modo de conclusión}

El acoplamiento en legitimidades sociales propias de la racionalidad instrumental ha tendido a resignificar mianzi (面子) como una eficiente estructura simbólica cuya meta es el lucro y el éxito económico, incentivando la libertad individual y la competencia. Un elemento que explica este tránsito se encuentra en la propia constitución del valor de mianzi, enmarcado en principios de reciprocidad que contienen tanto movimientos solidarios como agonísticos. Es precisamente este último movimiento el que se articula con patrones de consumo y derroche ostentatorio definidos generalmente por su valor en el mercado. La actual hegemonía de mianzi sobre liăn (脸) apunta en ese sentido.

Pese a este acoplamiento "modernizante", la misma lógica agonística de mianzi sostiene cadenas de reciprocidades basadas en la deuda social, muchas veces consolidando redes de jerarquías bastante distanciadas de la lógica del reconocimiento igualitario-democrático que caracterizaría a la modernidad occidental.

Las legitimidades "arcaicas", basadas en la deuda concreta del acuerdo personal o familiar, han pasado a cohabitar con aquellas cuyo fundamento es la deuda abstracta con el Estado o la institucionalidad del capital financiero, configurando un nuevo escenario de pugnas y alianzas dentro del grupo. Se observa así un espacio social en el que conviven sujetos cuyas prácticas transitan — no sin conflicto- entre el acuerdo particularista, contextual, característico del don, y la universalidad abstracta de la ley y el mercado.

Pese a las tiranteces que provoca la irrupción de la nueva escena, ésta no se constituye a partir de un simple reemplazo de un "estadio anterior". Al contrario, el ideal de ser empresario y la emergencia de un nuevo imperativo ético impulsado por el Estado chino, condensado en la fórmula del empresario-ru, responde a una lectura de los valores confucianos más tradicionales, enlazándose así con antiguas prácticas culturales. Esto explicaría en gran medida la legitimidad del mianzi asociado no al cálculo racional sino al "derroche" colectivo u ostentatorio, en tanto los individuos que han logrado traspasar ciertos niveles de acumulación y consumo personal, junto con ganar liderazgo, consolidan y acrecientan su mianzi con donaciones públicas que ratifican su honor y superioridad.

Al observar estos mecanismos, resulta evidente que las estructuras de origen han marcado decisivamente las disposiciones y prácticas de los chinos de España, 
permitiendo el engarce y el éxito económico en la sociedad de llegada. Para lograr dicha meta un apoyo decisivo lo han encontrado en profundas redes basadas en la lógica del don, que operan de forma ambivalente tanto en el reparto comunitario como en la rivalidad y el antagonismo. Al menos discursivamente, en ellas no siempre está presente el cálculo egoísta de una cuenta racional y exacta de lo que se espera a cambio, pues según su legitimidad interna el bienestar particular coincidiría con el del grupo. Sin embargo, en el caso analizado, esta moral "arcaica" tiende a desvelar la faz aristocrática que la constituye, potenciando sus mecanismos agonísticos, momento en el cual el acto de dar se inclina más a consolidar las jerarquías tradicionales que a posibilitar la movilidad en su seno.

\section{Referencias bibliográficas}

BATAILLE, George.

1987 [1947] La parte maldita. Barcelona: Icaria.

BELTRÁN, Joaquín.

1996 Parentesco y organización social en los procesos de emigración internacional chinos: del sur de Zhejiang a Europa y España. Tesis doctoral. Facultad de Ciencias Políticas y Sociología. Universidad Complutense de Madrid.

2003 Los ocho inmortales cruzan el mar. Barcelona: Bellaterra.

BELL, Daniel A.

2008 CHINA'S New Confucianism. Politics and everyday life in a changing society. Princeton/Oxford: Princeton University Press.

BOURDIEU, Pierre.

1997 Razones prácticas. Sobre la teoría de la acción. Barcelona: Anagrama.

CAI Kejiao.

1999 "Wenzhou renwen jingshen chutan" (An Analysis of the Wenzhou Ethos). Bulletin of Zhejiang Normal University (Social Science Edition), 2: 28-31.

CONFUCIO.

1998 Analectas. Madrid: EDAF.

DUBAR, Claude.

2002 La crisis de las identidades. Barcelona: Bellaterra.

DUMONT, Louis.

1977 Homo aequalis : genèse et épanouissement de l'idéologie économique. Paris : Gallimard.

EARLEY, Christopher.

1997 Face, harmony, and social structure: An analysis of organizational behavior across cultures. New York: Oxford University Press. 
FERNÁNDEZ STEMBRIDGE, Leila.

1998 Movimientos migratorios internos en la República Popular China contemporánea: una aproximación interpretativa. Memoria DEA. Facultad de Ciencias Económicas y Empresariales. Universidad Autónoma de Madrid.

FREUD, Sigmund.

2009 [1905] Tres ensayos sobre teoría sexual. Madrid: Alianza.

GODELIER, Maurice.

1996 L'énigme du don. Paris : Librairie Fayard/Flammarion.

GOFFMAN, Erwin.

2005 [1955] "On face-work: An analysis of ritual elements in social interaction". Psychiatry: Journal of Interpersonal Relations, 18 (3): 213-231.

GUTHRIE, Douglas.

1998 "The declining significance of guānxi in China's economic transition". China Quarterly, 154: 254-288.

HAMMOND, S.C.; GLEND, L.M.

2004 "The ancient practice of Chinese social networking: Guānxi and social network theory". Emergence: Complexity and Organization, 6: 24-31.

HO, David Yao-fai.

1974 "Face, Social Expectations, and Conflict Avoidance", en J. Dawson y W. Lonner (eds.), Readings in Cross-cultural Psychology: Proceedings of the inaugural meeting of the international association for cross-cultural psychology held in Hong Kong. Hong Kong: Hong Kong University Press, 240-251.

1976 "On the Concept of Face". The American Journal of Sociology, 81: 867-884.

HSU, Carolyn L.

2007 Creating Market Socialism. How ordinary people are shaping class and status in China. Durham/London: Duke University Press.

HU Hsien-Chin.

1944 "The Chinese Concept of Face". American Anthropologist, 46: 45-64.

HUTCHINGS, Kate; MURRAY, Georgina.

2002 "Working with guānxi: an assessment of the implications of globalization on business networking in China". Creativity and Innovation Management, 11: 184-91.

HWANG Kwang-Kuo.

1987 "Face and Favor: The Chinese Power Game". The American Journal of Sociology, 92: 944-974.

KOJEVE, Alexandre.

1975 [1947] Introduction à la lecture de Hegel. Paris: Gallimard.

LACAN, Jacques.

1985 [1958] "La significación del falo", en Escritos. México: Siglo XXI. 
LACAN, Jacques.

1990 [1961] Seminario VIII. México: Siglo XXI.

LI Zehou.

1997 "Chu ni ruxue shenceng jiegou jiangshuo" (An account of my initial thoughts on the deep structure of ruxue), en Li Minghui (ed.) Rujia sixiang de xiandai quanshi (Modern interpretations of rujia thought). Taipei: Zhongyang yanjiuyuan, Zhongguo wenzhe yanjiusuo choubeichu.

LI Jian.

1997 “Qian tan 'rushang ren' ge'” (The personality of the rushang). Zhexue dongtai, 12: $19-21$.

LIN Yü-tang.

1935 My Country and my People. New York: Reynal and Hitchcock.

LU Xun.

1934 “On Face”. En Selected Works of Lu Hsün, Vol. 4. Peking: Foreign Language Press, 129-132.

MAKEHAM, John.

2008 Lost soul. "Confucianism" in contemporary Chinese academic discourse. Cambridge (Massachusetts)/London: Harvard University Asia Center.

MAUSS, Marcel.

2008 [1924] "Essai sur le don. Forme et raison de l'échange dans les sociétés archaïques", en Sociologie et anthropologie. Paris: PUF.

MILLINGTON, Andrew; EBERHARDT, Markus; WILKINSON, Barry.

2006 "Guānxi and supplier search mechanisms in China". Human Relations, 59 (4): 505-532.

MINISTERIO DE TRABAJO E INMIGRACIÓN.

2010 Anuario estadístico de información. http://extranjeros.mtin.es/es/Informacion Estadistica/Anuarios/ (página consultada el 25 de febrero 2010).

MINISTERIO DE TRABAJO E INMIGRACIÓN.

2007 II Anuario de la Comunicación de Inmigrante. Madrid: Etnia Comunicación.

MORAGA, Jorge.

2010 Chinos en Asturias. La reciprocidad en el imperio del cálculo. Gijón: Muséu del Pueblu d'Asturies.

NIETO, Gladys.

2007 La Inmigración China en España. Una comunidad ligada a su nación. Madrid: Catarata/UAM.

OBSERVATORIO PERMANENTE DE LA INMIGRACIÓN (OPI).

2005 Las redes sociales de los inmigrantes extranjeros en España. Un estudio sobre el terreno. Madrid: Ministerio de Trabajo e Inmigración/Secretaría de Estado de Inmigración y Emigración. 


\section{PARTIDO COMUNISTA CHINO (PCCh).}

1983 "Documento N¹: Cuestiones sobre la actual política económica rural", en "Diez documentos $\mathrm{N}^{\mathrm{o}} 1$ de la dirección central para impulsar la reforma en el campo". Spanish. China.org.cn: http://spanish.china.org.cn/china/archivelianghui2008/2008-02/19/ content_10184409.htm (página consultada el 11 de octubre de 2010).

SHIRK, Susan.

1993 The Political Logic of Economic Reform in China. Berkeley: University of California Press.

WANG Dian-qing (Ed.).

2000 Dazhong daode (Moral for the masses). Beijng: Hongqi.

WEBER, Max.

1987 [1921] Ensayos sobre sociología de la religión. Tomo I. Madrid: Altea/Taurus/ Alfaguara.

YAN Yunxiang.

1996 The Flow of Gifts: Reciprocity and Social Networks in a Chinese Village. Stanford: Stanford University Press.

YÜ Ying-shi.

1987 Zhongguo jinshi zongjiao lunli yu shangren jingshen (Early modern Chinese religious ethics and the mercantile spirit). Taipei: Lianjing.

ZHANG Desheng.

2002 Rushang yu xiandai shehui: yi li guanxi de shehuixue zhi bian (Rushang and modern society: sociological distinctions regarding what is right and what is beneficial). Nanjing: Nankai daxue.

ZUFFEREY, Nicolas.

2007 "De Confucius au romancier Jin Yong”, en Anne Cheng (ed.), La Pensée en Chine aujourd'hui. Paris: Gallimard, 75-99.

ZURNDORFER, Harriet T.

2004 Confusing Confucianism with Capitalism: culture as impediment and/or stimulus to Chinese economic development. Comunicación en el III Global Economic History Network Wokshop, Konstanz. http://www.lse.ac.uk/collections/ economicHistory/GEHN/GEHNPDF/ConfusingConfucianismwithCapital ism-HarrietZurndorfer.pdf (página consultada el 12 de febrero de 2008). 